ISSN: 0514-7336

DOI: http://dx.doi.org/10.14201/zephyrus201473109132

\title{
COBRE PARA LOS MUERTOS. ESTUDIO ARQUEOMÉTRICO DEL MATERIAL METÁLICO PROCEDENTE DEL MONUMENTO MEGALÍTICO PREHISTÓRICO DE CASTILLEJO DEL BONETE (TERRINCHES, CIUDAD REAL)
}

\section{Copper for dead. Archaeometric study of metal objects from the prehistoric megalithic monument Castillejo del Bonete (Terrinches, Ciudad Real)}

Ignacio Montero Ruiz*, Luis Benítez de Lugo Enrich**, Honorio Javier Álvarez García***, P. Carolina Gutiérrez-Neira*, Mercedes Murillo-Barroso*, Norberto Palomares Zumajo***, Gabriel Menchén Herreros ${ }^{* * *}$, Jaime Moraleda Sierra*** y Domingo C. SAlazAr-García****

* Instituto de Historia. CCHS-CSIC. Cl Albasanz, 26-28. 28037 Madrid. Correo-e: ignacio.montero@cchs.csic.es ** Dpto. de Prehistoria y Arqueología. UNED-Ciudad Real. Aptdo. de Correos 238. 13300 Valdepeñas (Ciudad Real).Correo-e: lbenitez@valdepenas.uned.es

*** ANTHRopos, S.L. Aptdo. de Correos 238. 13300 Valdepeñas (Ciudad Real). Correo-e: anthropos@estudioarqueologia.es

**** Dpt. of Human Evolution. Max-Planck Institute for Evolutionary Anthropology. Deutscher Platz 6. 04103

Leipzig.Correo-e: domingo_carlos@leva.mpg.de

Recepción: 13/02/2013; Revisión: 31/05/2013; Aceptación: 18/02/2014

BIBLID [0514-7336 (2014) LXXIII, enero-junio; 109-132]

RESUMEN: Castillejo del Bonete es una cueva que fue utilizada y adaptada como monumento funerario durante la Prehistoria reciente. Abundantes piezas metálicas en óptimo estado de conservación se han recuperado de los túmulos construidos encima de la cueva, tanto en el interior de tumbas como fuera de ellas.

El objetivo de este trabajo es presentar la colección metálica del yacimiento recuperada hasta finales de 2012. También el estudio arqueometalúrgico de varias de las piezas y una interpretación del conjunto en relación a su ámbito cultural y territorial. La investigación además incorpora datos inéditos de El Acequión, Albacete, para proporcionar una perspectiva comparativa sobre la procedencia del metal en la Edad del Bronce con los datos disponibles del área argárica.

Las piezas metálicas son explicadas en sus respectivos contextos arqueológicos antes de ser analizadas por diferentes métodos y técnicas: isótopos de plomo, espectrometría por fluorescencia de rayos X, microscopía electrónica de barrido con microanálisis por espectrometría de dispersión de energías de rayos X, metalografía y análisis de microdureza.

Los resultados revelan tipos y procesos metalúrgicos característicos del Calcolítico y fases antiguas de la Edad del Bronce. En general son piezas sin estaño pero con alto contenido en arsénico, procedentes en buena parte del área de Linares.

Palabras clave: Edad del Bronce. Calcolítico. Cueva. Túmulo funerario. Cobre arsenicado. Isótopos de plomo. Arqueometalurgia. Cultura de las Motillas. 
ABstract: Castillejo del Bonete is a cave adapted as a funerary monument during Late Prehistory. Various well-preserved metal objects were recovered from the site, both within and outside the graves.

This paper presents a catalogue and analysis of the metal objects recovered before the end of 2012, and comprises results obteined from archaeometallurgical studies and an interpretation of their cultural and territorial context. Unpublished data from El Acequión, Albacete, is also presented to provide a comparative perspective on the provenance of metal during the Bronze Age.

The metal artefacts were archaeologically contextualized prior to analyses, wich included lead isotopes, XRF spectrometry, SEM microanalysis, metallography and microhardness analysis.

Our results reveal the use of various types of metals and the application of metallurgicall processes associated with Chalcolithic and ancient Bronze Age phases. Overall, the results obtained showed that the metal artefacts analysed did not contain tin, but high levels of arsenic, probably originating from the area of Linares (Jaén).

Key words: Bronze Age. Chalcolithic. Arsenic cooper. Lead isotopes. Cave. Burial mound. Archaeometallurgy. Las Motillas Culture.

\section{Introducción}

Los trabajos de excavación arqueológica en Castillejo del Bonete comenzaron en 2003 promovidos por el Ayuntamiento de Terrinches, bajo supervisión y con autorización de la Junta de Comunidades de Castilla-La Mancha ${ }^{1}$. El lugar se encuentra en el borde meridional de la Meseta castellana y en la comarca del Campo de Montiel, al SE de la provincia de Ciudad Real (Fig. 1).

El monumento fue utilizado durante el Calcolítico y las primeras fases de la Edad del Bronce, como se detallará más adelante. Fue construido sobre una ladera orientada al $\mathrm{S}$, desde la cual hay una excelente relación visual con una importante vía de comunicación histórica entre el Levante, la Submeseta Sur y la Alta Andalucía: la Vía Augusta

\footnotetext{
${ }^{1}$ Agradecemos al Ayuntamiento de Terrinches, y especialmente a su alcalde N. Peláez, su apoyo institucional, económico y logístico, sin el cual la investigación sobre Castillejo del Bonete no habría sido posible. También agradecemos a C. Martín Morales y a R. Sanz, directora del Museo de Albacete, las facilidades para el estudio con isótopos de plomo de los metales de El Acequión y a M. I. Martínez Navarrete la autorización para utilizar los análisis de isótopos de plomo tanto de Castillejo de Bonete como de El Acequión, realizados dentro del proyecto "Provincias metalúrgicas Euroasiática y Europea del II milenio a.n.e.: investigación de sus interacciones a partir de métodos científico-naturales", cofinanciado en 201112 por el CSIC y la Russian Foundation For Basic Research (n. ${ }^{\circ}$ referencia 2010RU0086). A. Gómez Morón y J. Simón han analizado el puñal con muescas (Fig. 3, n. ${ }^{\circ}$ 1), el puñal de remache (Fig. 3, n. ${ }^{\circ} 3$ ) y el punzón (Fig. 4 , n.o 1) encontrados en la Tumba 4.

Este trabajo se publica con la autorización expresa de la Dirección General de Cultura de la Junta de Comunidades de Castilla-La Mancha (Exp. Cultura 13-0041).
}

(Benítez de Lugo et al., 2012; Sánchez Sánchez et al., 2012). El lugar es un paso estratégico entre las cuencas del Guadiana y del Guadalquivir, separadas por Sierra Morena.

La localización de Castillejo del Bonete al SE de la provincia de Ciudad Real lo ubica en el borde meridional del territorio en el que tradicionalmente se ha situado a la Cultura del Bronce de La Mancha, si bien es conveniente recordar que las fronteras precisas de esta cultura están poco estudiadas y se hallan pendientes de definición.

$\mathrm{Al}$ poco tiempo de comenzar los trabajos en el yacimiento quedaron al descubierto potentes arquitecturas de planta central. En campañas posteriores se descubrió un largo pasillo ciclópeo de más de $20 \mathrm{~m}$ de longitud. También se detectó bajo esos potentes muros una cueva que era desconocida y al comienzo de los trabajos estaba oculta. En el momento actual se ha hecho evidente la existencia de un gran túmulo edificado sobre una cueva natural, rodeada en su boca de potentes muros de contención que evitaban que las acumulaciones de tierra y piedras penetraran al interior de las galerías subterráneas. Según se desprende de las evidencias disponibles en este momento parece probable la existencia en los alrededores tanto de otros túmulos como de alguna cabaña entre las estructuras pendientes de excavación.

Estos hallazgos y el avance de las investigaciones $^{2}$ desarrolladas en 2012 (Benítez de Lugo et al.,

2 Benítez de Lugo, L.; Álvarez, H. J.; Palomares, N.; Mata, E. y Moraleda, J.: "Investigación de un complejo monumental prehistórico en el borde meridional de la Meseta: Castillejo del Bonete (Terrinches, Ciudad Real). Una década de intervenciones arqueológicas (20032012)", Arse, 48, en prensa. 
2014a, 2014b) han permitido determinar que en Castillejo del Bonete hay una cueva que hace las funciones de cámara funeraria y que fue monumentalizada y adaptada para su uso en tiempos prehistóricos, resultando sellada y cayendo en el olvido tras el abandono del monumento durante la Edad del Bronce (Salazar et al., 2013) $)^{3}$.

Los materiales hallados en Castillejo del Bonete son otra muestra de la complejidad y singularidad de este yacimiento del interior peninsular. Al material cerámico -utilizado como ajuar en varias tumbas y con formas presentes en poblados calcolí-

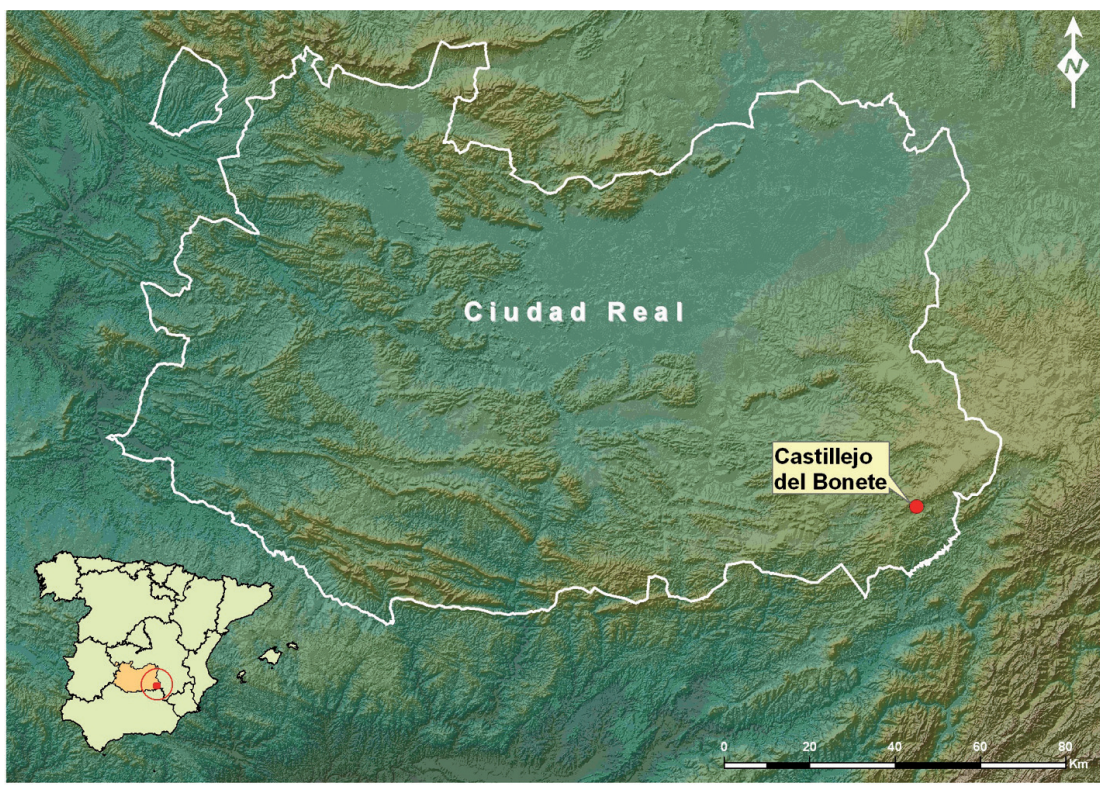

FIG. 1. Plano general de localización de Castillejo del Bonete (Terrinches, Ciudad Real). ticos y de la Edad del Bronce de la región- se suma el abundante material lítico y el muy abundante material metálico. Se han encontrado también varias piezas de marfil -algunas asociadas a enterramientos- y cuentas de variscita junto a varias moscovitas sin tallar ${ }^{4}$.

A continuación presentamos en detalle el estudio arqueométrico realizado sobre las piezas metálicas recuperadas. En primer lugar presentaremos su contexto arqueológico, para seguidamente describir los resultados de las técnicas de análisis empleadas y, finalmente, exponer una interpretación de los análisis realizados.

${ }^{3}$ Cf. también Benítez de Lugo, L. et al.: op. cit. n. 2; Benítez de Lugo, L.; Álvarez, H. J.; Fernández Martín, S.; Mata, E.; Menchén, G.; Montero, I.; Moraleda, J.; Morgado, A.; Palomares, N.; Benito, M.; Odriozola, C.; RuizAlonso, M. y Salazar-García, D. C.: "Castillejo del Bonete (Terrinches, Ciudad Real): complejo tumular prehistórico en el Alto Guadalquivir”, Menga, Revista de Prehistoria de Andalucía, 5, en prensa.

${ }^{4}$ Benítez de Lugo, L.; Palomares, N.; Fernández Martín, S.; Mata, E.; Menchén, G.; Montero, I.; Moraleda, J.; Morgado, A.; Álvarez, H. J.; Benito, M.; Odriozola, C.; Ruiz-Alonso, M. y Salazar-García, D. C.: "Materiales arqueológicos de Castillejo del Bonete (Terrinches, Ciudad Real): estudio analítico y contexto cultural”. Menga. Revista de Prehistoria de Andalucía, 6, en prensa.

\section{Contexto arqueológico de los metales}

Los materiales arqueológicos metálicos exhumados en el yacimiento se han encontrado por toda la superficie excavada y podrían agruparse en cuatro clases atendiendo a su deposición: depósitos en ritos funerarios, depósitos intencionados cerrados, materiales derivados por procesos postdeposicionales y metales hallados in situ en el interior de la cueva-cámara (Fig. 2).

\subsection{Metales depositados en ritos funerarios}

En el primer grupo han de ser incluidos dos puñales y un punzón -clase de piezas que presenta uno de sus extremos aguzado y otro romo- que formaban parte del ajuar de la Tumba 4, además una punta de flecha asociada al complejo rito de enterramiento practicado sobre los dos individuos contenidos en ella. Esta tumba fue construida dentro de un recinto exterior anexado a los potentes muros que rodean el acceso a la cueva. El Dpto. de Ciencias de la Tierra de la Universidad de La Sapienza-Roma, tomando como base para la analítica el colágeno del fémur del Individuo 2 -probablemente el que fue enterrado en primer 


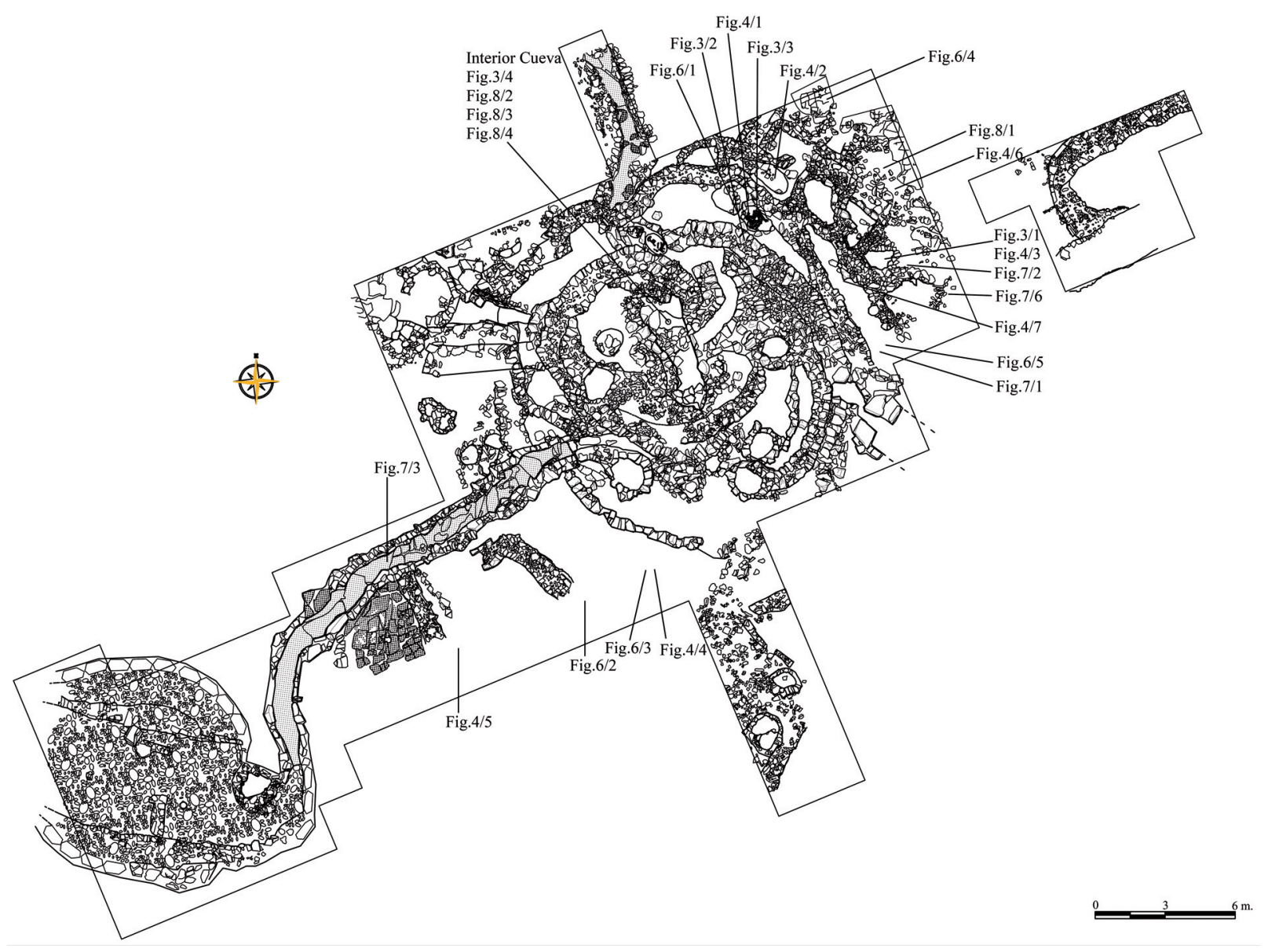

FIG. 2. Planta de Castillejo del Bonete y localización de los hallazgos metálicos (@) Enrique Mata Trujillo).

lugar-, proporcionó para este conjunto una datación radiocarbónica de 3720 BP \pm 70 (Rome1687; cf. calibraciones en la Fig. 22).

Uno de los puñales encontrados en esta Tumba 4 es de lengüeta con un remache (Fig. 3, n. ${ }^{\circ}$ 3) y apareció al lado de la cadera del Individuo 2, que fue enterrado con un brazal de arquero en su antebrazo. En torno al remache parecen conservarse restos del mango de madera y sobre la hoja del puñal se aprecian adherencias de su funda de cuero, fabricada con piel de cabra y parasitada por artrópodos de la clase de los crustáceos -orden de los isópodos-, cuya impronta permanece fosilizada sobre la pieza. Su hoja es plana y triangular, y la lengüeta no está diferenciada, siendo también de tendencia triangular. Dentro de la Cultura del Bronce de La Mancha, en la provincia de Ciudad Real, se han encontrado puñales de este tipo en el Cerro de La Encantada (Granátula de Calatrava), siendo el ejemplar más parecido el procedente del Cerro de las Viñas (Coy, Murcia) (Brandherm, 2003: lám. 24, n. ${ }^{\circ}$ 347).

El segundo puñal también con un remache -hoy perdido- en la lengüeta presenta dimensiones menores que el anterior, posiblemente por el reafilado (Fig. 3, n.o 2). La lengüeta es de tendencia trapezoidal y está poco marcada. Este cuchillito fue depositado junto con un punzón dentro de la olla globular que formaba parte del ajuar de esta tumba (Fig. 4, n. ${ }^{\circ}$ 1). La olla se ha conservado íntegra hasta nuestros días y colmatada de sedimento arqueológico, sin que las analíticas realizadas sobre sus paredes - de PH, textura de la fracción fina, carbonatos, calcio, cloruros, fosfatos, 
lípidos, carbohidratos y fitolitos- hayan permitido detectar traza de elemento alguno. De ello puede concluirse que fue depositada junto a los muertos con un fin ritual y vacía, a excepción del punzón y del pequeño puñal desgastado contenidos en su interior (Fig. 5).

Es interesante señalar que los dos individuos enterrados en la Tumba 4 no fueron inhumados simultáneamente. Primero fue enterrado el Individuo 2, debiendo ser reabierta la tumba para depositar junto a él al Individuo 1. Junto al húmero derecho de este último se encontraron dos grandes botones de marfil de perforación en $\mathrm{V}$ que el difunto debía llevar cosidos a su ropa a la altura del pecho. Los botones conservaban fibra vegetal en su perforación, posiblemente esparto. La analítica realizada a estas piezas indica que los botones sufrieron un largo proceso de cremación, que los contrajo y fragmentó.

Las evidencias arqueológicas indican que tras disponer el segundo cadáver en la Tumba 4, una vez cerrada esta con tierra, se encendió encima un fuego cuya temperatura afectó a parte de los dos esqueletos de los individuos allí inhumados. En la hoguera, probablemente como parte del rito desarrollado en honor de los difuntos, se depo-

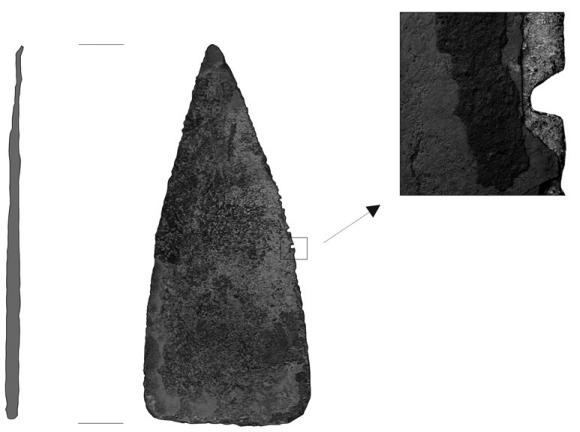

1 TE 05 BO F12 UE 76

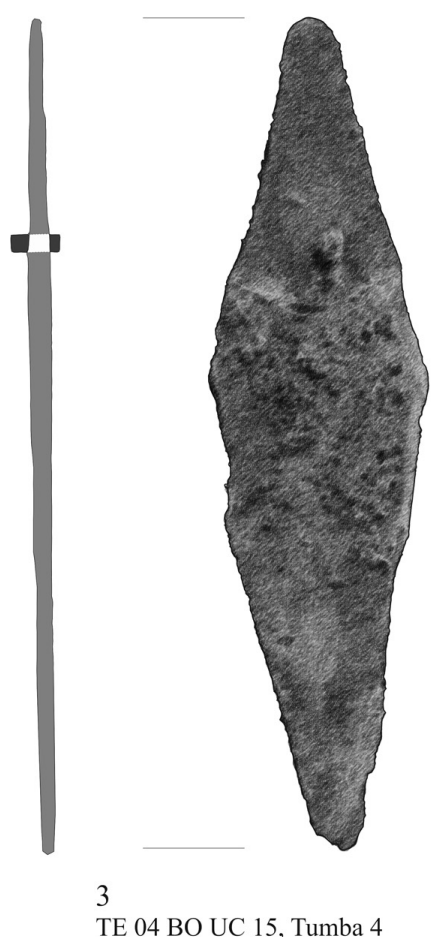

TE 04 BO UC 15, Tumba 4

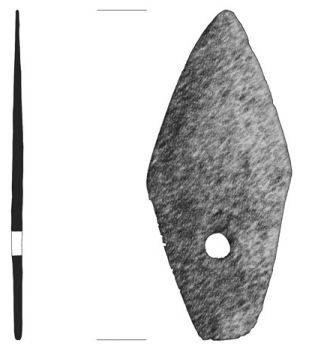

2 TE 04 BO UC 15, Tumba 4
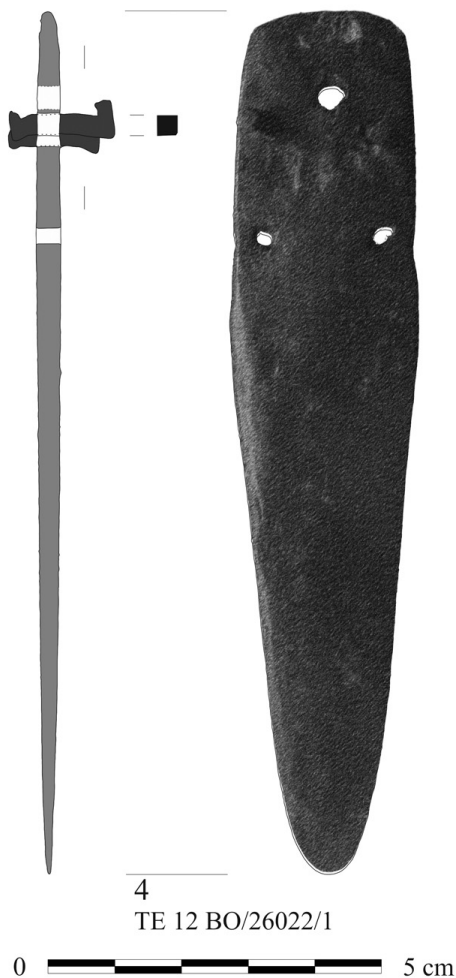

FIG. 3. Puñales y cuchillos de Castillejo del Bonete. sitó o arrojó la punta de flecha tipo Palmela que constituye el último objeto metálico de este conjunto (Fig. 6, n. ${ }^{\circ} 1$ ). Su hoja es plana, ovalada y presenta un bisel marginal en los bordes. La pieza cuenta con un pedúnculo que fue doblado y no es excesivamente largo, atendiendo a la proporción largo/ancho del mismo respecto a la hoja. Al no superar los $8 \mathrm{~cm}$ de longitud la pieza se describe como corta; igualmente es estrecha, al no superar los 2,4 cm de anchura. Formalmente se englobaría en el tipo B de Delibes (1977). Dentro de la provincia de Ciudad Real hay útiles similares en el Cerro de la Encantada, aunque son ligeramente más largos -unos 9,5 cm-. La distribución de las palmelas es muy amplia a nivel peninsular.

\subsection{Metales intencionalmente depositados}

El apartado de los depósitos intencionados ha aportado un buen número de piezas asociadas a 


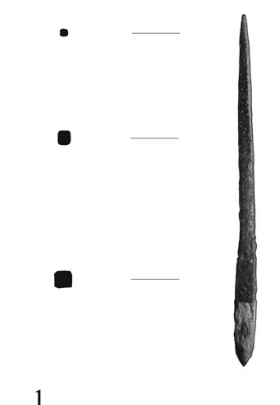$$
\text { TE } 04 \text { BO UC 15, Tumba } 4
$$

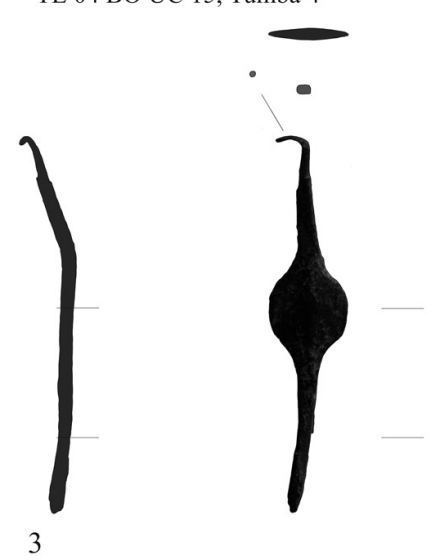

TE 08 BO G12 UE 76

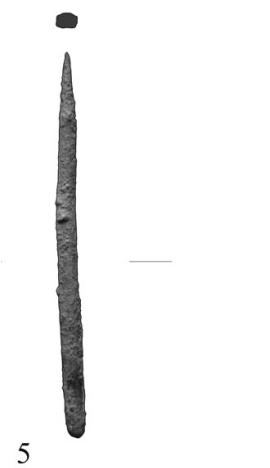

TE 08 BO K1 UE 114
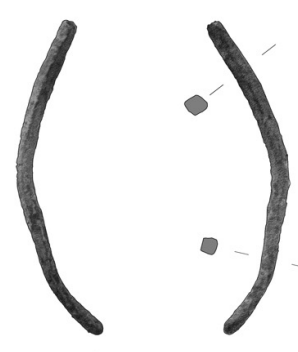

2

TE 05 BO D 11 UE 34

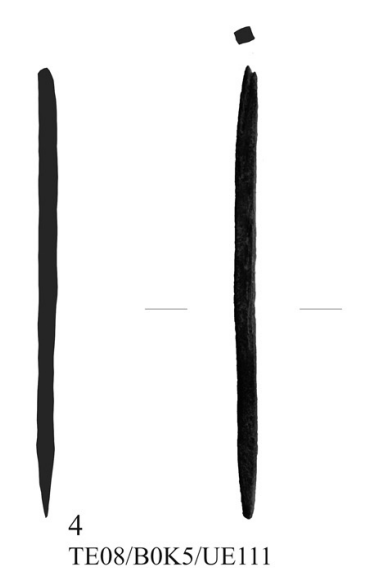

TE08/B0K5/UE111
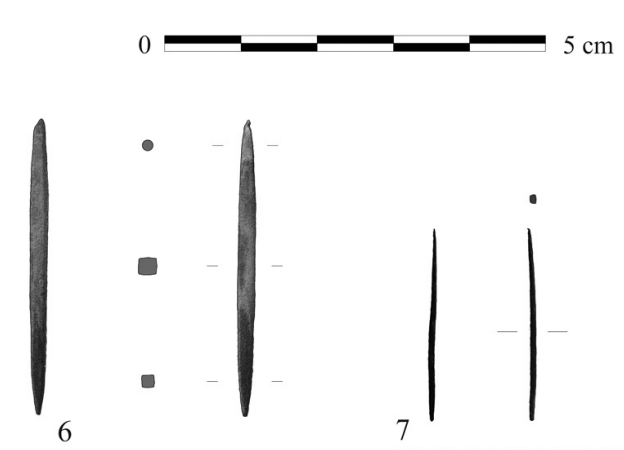

TE 08 BO E 13 UE 77

FIG. 4. Punzones y agujas de Castillejo del Bonete.

otros materiales arqueológicos, algunos de ellos singulares. La intencionalidad de estos depósitos podría relacionarse con el mundo de ultratumba aparejado a la carga simbólica del yacimiento, al menos en su zona central, expresada en sus potentes muros concéntricos dispuestos en torno a la entrada de la cueva, el corredor ciclópeo y la propia cueva. Estos depósitos se caracterizan por encontrarse en reducidos espacios enmarcados en sencilla mampostería, con formas que oscilan del círculo al cuadrilátero, pasando por el óvalo. Estas pequeñas fosas u hoyos albergan en su interior un variopinto inventario de materiales arqueológicos de funcionalidad doméstica y uso cotidiano junto a otros considerados como de prestigio, entre los cuales los metálicos ocupan un lugar destacado.

Una de estas piezas es un fragmento metálico de sección circular, de unos 5 $\mathrm{cm}$ de longitud, cuya adscripción tipológica es sumamente complicada por el hecho de no hallarse completo (Fig. 4, n. ${ }^{\circ} 2$ ); podría tratarse de un aguja o punzón roto y doblado. Se ha recuperado dentro de un recinto de planta cuadrangular que no está completamente excavado, por lo que no es posible establecer sus dimensiones totales. En su interior alberga, además del reseñado fragmento de bronce, gran cantidad de material cerámico -cabe destacar un notable fragmento de vaso colador-, restos de fauna, un colgante fusiforme perforado elaborado en hueso y pequeños restos de carbón. Toda la unidad podría interpretarse como una zona votiva en la que fueron depositadas ofrendas variadas, debido a la heterogeneidad del material aportado.

En otro recinto de este tipo se han encontrado dos objetos metálicos de notable interés: un puñal con muescas en el filo (Fig. 1, n.o 1) y una curiosa pieza sin paralelos conocidos que podría relacionarse con los denominados punzonesbrújula por su engrosamiento central (Fig. 4, n.o 3). Mide $5 \mathrm{~cm}$ de longitud con ambos extremos puntiagudos, aunque de distinto calibre y sección -una circular y otra cuadrangular-; en el centro, la pieza presenta un engrosamiento de forma circular.

Ambos objetos se han localizado intramuros de una estructura de planta cuadrangular que no está en la actualidad completamente excavada y subyace a otras construcciones edificadas posteriormente de planta curva. No obstante, la matriz sedimentaria que colmata esta unidad estratigráfica 
ha sellado el interior del recinto y carece de alteraciones postdeposicionales en su contenido, por lo que puede afirmarse que los materiales exhumados dentro de esta estructura se encuentran en posición primaria. Esta unidad aporta material arqueológico muy significativo y heterogéneo -cerámico, faunístico y lítico-, pero sin ningún género de duda las piezas más singulares de esta unidad son las dos piezas metálicas aludidas.

El puñal fue encontrado en posición vertical adosado a la cara interior del muro, en un agujero ubicado entre dos mampuestos. Es de pequeño tamaño -6 $\mathrm{cm}$ de longitud por 2,7 de anchura máxima- y está formado por la intersección de dos filos laterales simétricos y convergentes. Presenta en uno de sus laterales algunas muescas debido a pérdida de metal, probablemente producidas por el avance de la corrosión en

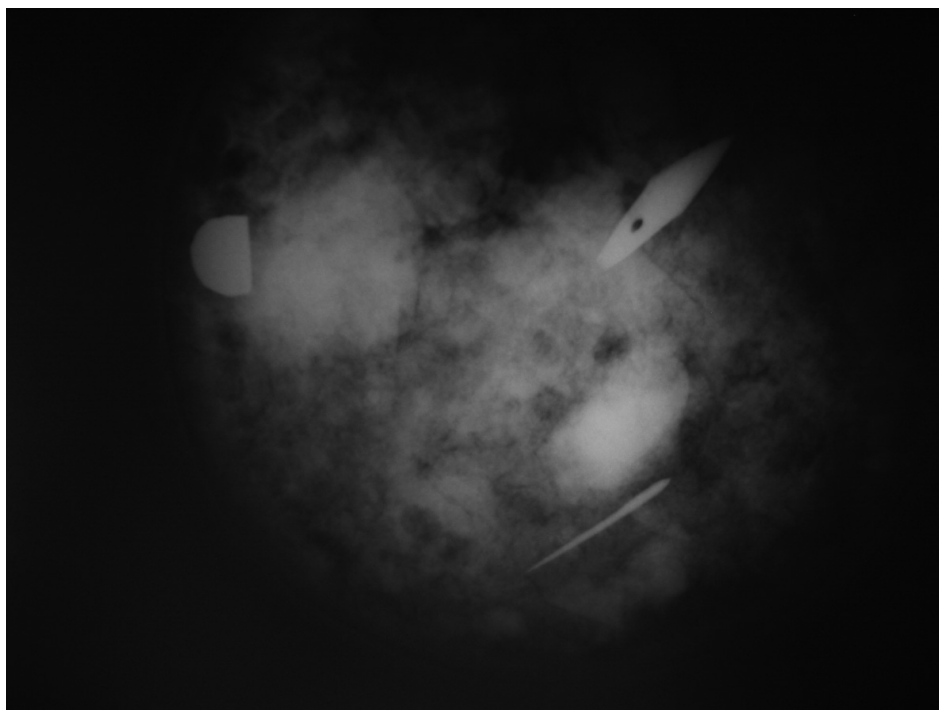

FIG. 5. Radiografía de la olla globular depositada como ajuar en la Tumba 4 de Castillejo del Bonete con 2 piezas metálicas en su interior (Fig. 3, n.o 2 y Fig. 4, n.o 1) (fotografía de Arqueocat). profundas presentan tendencia curva a diferencia de los dentados intencionales que lo hacen con perfil en V, y la zona entre muescas es completamente plana, lo que apunta a una falta de intencionalidad en su distribución. La parte proximal es recta, lo que sugiere que se trata de un fragmento de una pieza de mayores dimensiones retocada y adaptada redondeando ligeramente el borde en la zona de fractura. Además no se detecta ninguna zona de enmangue definida. En algunos puntos muy localizados del cuchillo se han identificado restos de fosfato cálcico, probablemente procedente de restos de huesos de fauna hallados en las proximidades.

Dentro del corredor ciclópeo se ha recuperado un cincel (Fig. 7, n.o 3). No se trata de un material en posición secundaria, derivado, sino que está asociado a una de las unidades estratigráficas localizadas en posición primaria y destinada al uso de este pasillo. Esta matriz sedimentaria aporta, además, material arqueológico abundante -cerámico, lítico y fauna, alguna de ella quemada-. Entre el cerámico destacan bordes rectos, exvasados, biselados, galbos bruñidos o espatulados, galbos con decoración incisa y fragmentos de cuello. No se han documentado piezas excepcionales claramente disociadas de las de funcionalidad cotidiana, siendo por tanto reflejo de la cerámica típica inventariada en el asentamiento, habitual en otros poblados de este ámbito cultural.

Extramuros al corredor ciclópeo se ha recuperado otra punta de flecha más, también del tipo Palmela. Si la anterior punta estaba doblada en su pedúnculo, esta se encuentra rota en su parte distal (Fig. 6, n.o 3). Se halló dentro de una unidad constituida por mampuestos y adobes derivados de su posición original que son las desaparecidas hiladas de un muro curvo que se adosa al corredor por su cara S. Este derrumbe es muy similar a otros inventariados en las zonas anexas a los muros más potentes del yacimiento y en su interior alberga numeroso y diverso material arqueológico significativo. Entre el material lítico se documentó un brazal de arquero, fragmentado, posiblemente reutilizado como colgante, que presenta una perforación circular en uno de sus extremos y una punta de flecha de sílex de pedúnculo en excelente estado de conservación. No menos destacada resulta la presencia de dos láminas de sílex, piezas en piedra pulimentada, un canto rodado, abundante cuarcita y tres fragmentos de molinos barquiformes. En cuanto al material óseo 

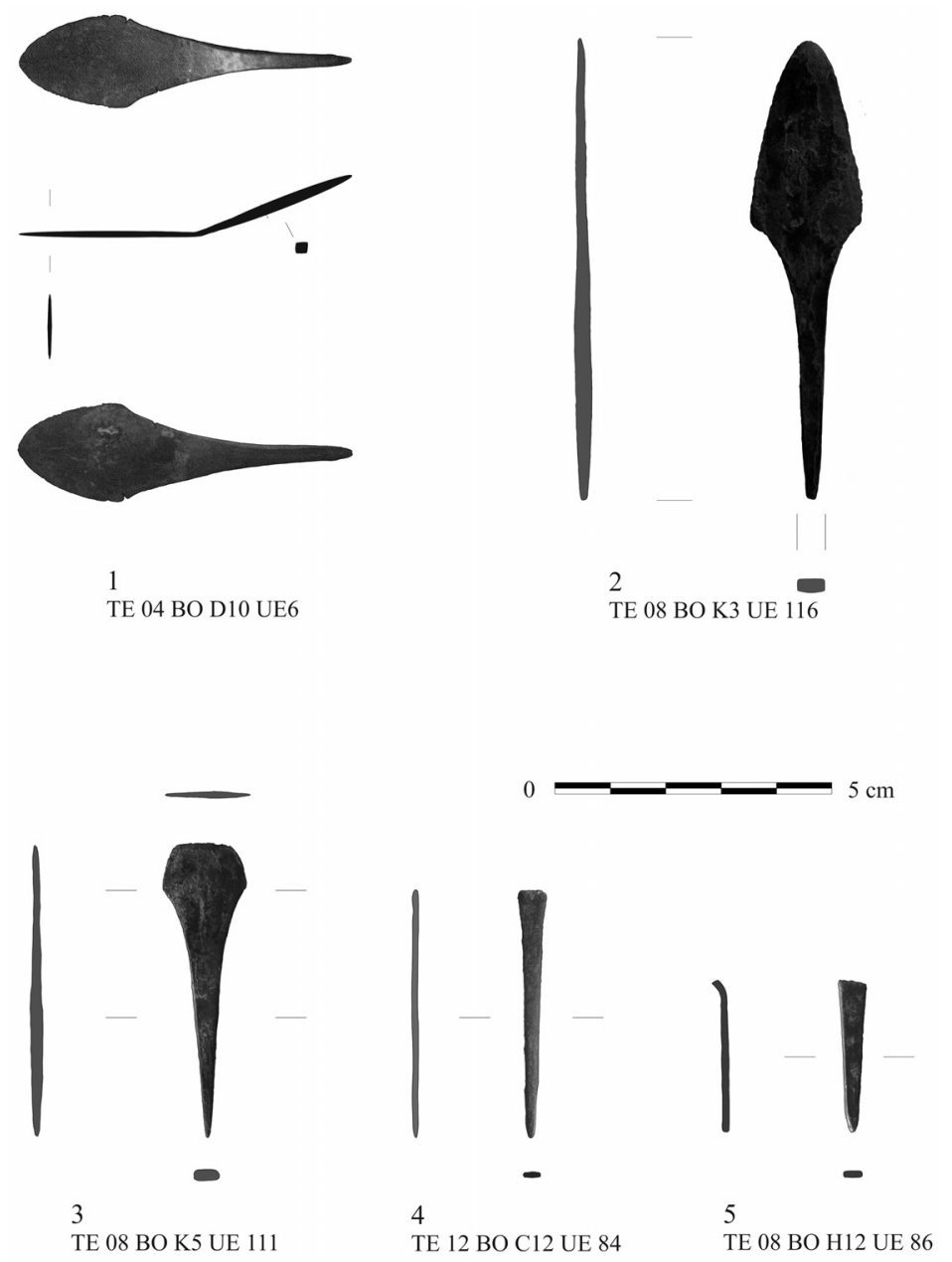

FIG. 6. Flechas de Castillejo del Bonete. parcialmente excavado, otra punta de flecha tipo Palmela en excelente estado de conservación, asociada a material arqueológico significativo (Fig. 6, n. ${ }^{\circ}$ 2); su longitud es de $8,5 \mathrm{~cm}$ y su anchura máxima de $2,2 \mathrm{~cm}$. Acompaña a esta pieza fauna abundante, con numerosos ejemplos de hueso quemado. El material más repetido es el cerámico, con un amplio y surtido repertorio de elementos. Destaca la presencia de un conjunto de cuenco hemiesférico cubierto por otro cuenco menor a modo de tapa. El material lítico asociado a esta punta de flecha está integrado por láminas de sílex, dos molinos de mano, cantos rodados, cuarcita y un fragmento de roca volcánica -que no procede de este entorno del Campo de Montiel y Sierra Morena-.

Un punzón de sección cuadrada de 5 $\mathrm{cm}$ de longitud ha sido encontrado en otra unidad estratigráfica, separada de la anteriormente descrita por un muro curvo dispuesto en dirección a la cara $\mathrm{S}$ del Corredor (Fig. 4, n. ${ }^{\circ}$ 5). Aunque este paramento está sólo parcialmente excavado, bien podría conformar un cuarto muro concéntrico en torno a la cueva. Esta matriz es de tono pardo oscuro, de textura muy suelta y arenosa. Su color podría resultar de la descomposición de materia orgánica. En su interior alberga destacado material arqueológico. Relativamente abundante es la presencia de

destaca la presencia de un colgante realizado a partir de un incisivo con perforación circular, posiblemente asociado al reseñado brazal de arquero. También se ha inventariado un fragmento de punzón sobre hueso. Completan el contexto arqueológico de este punzón abundante fauna -quemada o no- y cerámica varia, entre cuyas piezas destaca un pequeño cuenco cerámico de $3,4 \mathrm{~cm}$ de diámetro y 2,3 de altura. Este recipiente cuenta con un paralelo próximo en la Motilla del Azuer (Daimiel, Ciudad Real) asociado a un lugar funerario, en este caso un enterramiento infantil (Nájera et al., 2006: 154).

En este mismo espacio, inmediatamente bajo la unidad antes citada, se ha registrado, en un estrato cerámica diversa, destacando un cuenco hemiesférico en posición invertida apoyado directamente sobre la roca madre. Es interesante reseñar en esta unidad la presencia de malacofauna asociada a abundante material cerámico fragmentado. La fauna está aquí también abundantemente representada. Respecto al material lítico se han encontrado varios fragmentos de molino, una punta de flecha de sílex en muy buen estado de conservación, una lámina de sílex, cantos rodados, abundante cuarcita y dos hachas pulimentadas.

Otro pedúnculo de flecha carente de punta (Fig. 6, n. ${ }^{\text {4) }}$ ha sido localizado en el derrumbe de un recinto de planta rectangular. Aunque por el momento dicho recinto sólo ha sido parcialmente 
excavado y se encuentra en muy mal estado de conservación sí es posible señalar que previsiblemente su excavación completa aportará datos de interés, según se desprende de la calidad de los materiales que acompañan a esta pieza metálica: cerámicas carenadas con excelente bruñido, huesos de grandes herbívoros, huesos quemados, láminas de sílex, un hacha pulimentada, un fragmento de roca volcánica y un botón de marfil de perforación en $\mathrm{V}$, con forma trapezoidal, en cuyas perforaciones se conservan fibras vegetales - probablemente esparto-.

\subsection{Metales en contextos secundarios}

Otro grupo de metales lo constituyen las piezas asociadas a unidades estratigráficas que han sufrido algún tipo de alteración postdeposicional que ha provocado la deriva del material.

En este grupo se encuentran una aguja o lezna -útil con los dos extremos punzantes y más afilado que los punzones (Fig. 4, n. ${ }^{\circ}$ 7)-, un cincel -piezas de sección cuadrangular con un extremo romo y el otro biselado (Fig. 7, n. ${ }^{\circ}$ 2)-, otro punzón (Fig. 7, n. ${ }^{\circ} 1$ ) y un fragmento metálico indeterminado (Fig. 7 , n. $\left.{ }^{\circ} 4\right)$. Todos ellos han sido hallados en una matriz asociada extramuros de un pequeño recinto. Estas piezas podrían estar asociadas a las contenidas en el interior del recinto, encontrándose derivadas hacia el exterior por afecciones postdeposicionales. En esta unidad se han inventariado excelentes trazas de barros compactos y tapiales de las construcciones adyacentes. Estos tapiales informan que los paramentos de los recintos curvos anexos eran, en los niveles superiores al zócalo, de mampostería, de tapial y barro compactado -posiblemente asociado a estructuras lígneas-, que tras su posterior ruina y colapso embutieron y soterraron los zócalos de mampostería. En este lugar junto a las piezas de metal resalta el material lítico, magníficamente representado por la presencia de artefactos en piedra pulimentada, uno de ellos
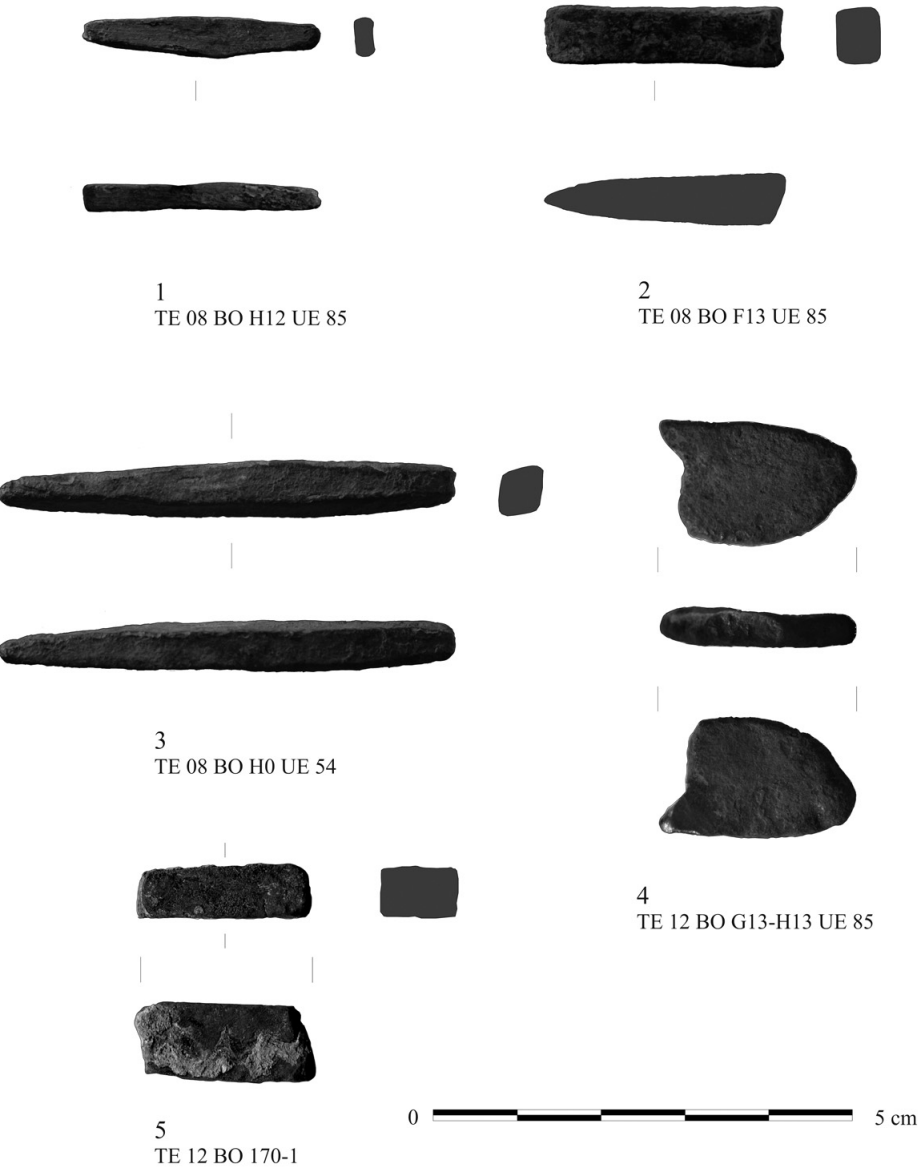

FIG. 7. Punzones, cinceles e indeterminados metálicos de Castillejo del Bonete.

un hachita votiva. Se ha recuperado también aquí una lámina de sílex, un canto rodado, lascas de cuarcita y un fragmento de roca volcánica. En cuanto al material óseo han sido identificados diversos fragmentos de fauna y restos de hueso quemado, aunque en número poco significativo. Más destacada es la presencia de un punzón sobre hueso. Los materiales cerámicos son abundantes.

Inmediatamente ubicada bajo esta unidad fue detectado un pedúnculo de flecha roto y doblado al inicio de la punta, que se encuentra desaparecida (Fig. 7, n. ${ }^{\circ}$ 5). Esta unidad estratigráfica resultó alterada por la construcción de estructuras prehistóricas posteriores a su momento de uso, por lo que los materiales que alberga se 
encuentran en posición secundaria. Un elemento a destacar dentro de esta unidad es un maxilar superior humano. Todo ello es material en posición derivada, por lo que no hay que descartar la presencia de una tumba desmantelada, removida y ya desaparecida. Es por ello que los distintos útiles podrían haberse encontrado en estrecha relación. Entre el material lítico cabe reseñar el hallazgo de varias lascas de cuarcita, cantos rodados y varias piezas pulimentadas, una de ellas una azuela. El material cerámico está claramente representado por un buen repertorio tipológico.

En este grupo cabe citar también un punzón apuntado en sus dos extremos; uno de sección cuadrada y otro circular (Fig. 4 , n. ${ }^{\circ}$ 6). Fue localizado junto a un recinto circular. Es una matriz de tono ocre claro, de textura muy suelta y arenosa, que alberga mampuestos de tamaño medio en posición derivada que la delimitan en sus extremos. Junto al punzón se han inventariado un buen número de materiales arqueológicos muy diversos y heterogéneos. El material cerámico está representado en porcentajes altos, destacando algunos ejemplos de bordes, galbos con decoración incisa y bruñidos. Entre el material lítico destacan un fragmento de hacha pulimentada, cuarcitas y una lámina de sílex. El aporte de material óseo es poco significativo, con una presencia de fauna meramente testimonial y restos de hueso quemado. Se ha identificado una pequeña bolsa de carbones.

Finalmente, un punzón (Fig. 8, n. ${ }^{\circ}$ 1) fue recuperado de un estrato de tierra muy suelta y arenosa, de tono pardo claro, con pequeños mampuestos de caliza de tamaño medio y guijarros. En esta unidad se encontraron además materiales arqueológicos muy diversos. Entre el material lítico destaca la presencia de un fragmento de cuchillo de sílex y numerosas lascas de cuarcita, además de una moledera. En cuanto al material óseo fueron encontrados varios fragmentos de hueso quemado y pulido. En principio estas piezas corresponden, bien a trozos óseos preparados para ser posteriormente trabajados, bien a restos y deshechos de dicha actividad descartados para la fabricación de útiles. En cuanto a la fauna, esta es bastante significativa, con un número moderado de fragmentos. Pero, sin duda, el material a destacar en esta matriz es el cerámico. El repertorio de tipologías de bordes es diverso y muy representado: exvasados, invasados, rectos, decorados con digitaciones, etc. Junto a ello hay cuellos, galbos bruñidos, algunos carenados, decorados con incisiones, bases, tapaderas -o fichas-, queseras y escasos fragmentos de bases.

Como punto final cabe destacar la presencia de un fragmento de la parte central de un cincel de cobre localizado en la colmatación de piedras del túmulo en su zona oeste (Fig. 7, n. ${ }^{\circ}$ 5). Se trata de un fragmento de cincel de cobre de 20 $\mathrm{mm}$ de longitud, $8 \mathrm{~mm}$ de anchura y $5 \mathrm{~mm}$ de espesor, asociado al relleno de piedras calizas realizado en el interior del túmulo, con intromisión de la UE92 entre el relleno de piedras calizas. El estrato tiene unas dimensiones de 5,7 $\mathrm{m}$ de longitud y 3,6 m de anchura. En su interior se han encontrado restos de varias formas cerámicas entre las que se encuentran restos de una olla globular grande de cuello indicado, una cazuela carenada grande, una fuente grande, una orza ovoide de cuello marcado y borde ligeramente abierto, una olla ovoide, una olla de forma indeterminada, una orza ovoide de cuello marcado y borde ligeramente abierto, una olla ovoide de cuello indicado, una fuente grande de borde curvo entrante, una olla globular grande de cuello indicado, una fuente grande, una fuente carenada, una olla de forma indeterminada, un cuenco semiesférico con incisiones en ambas caras de campaniforme tipo Dornajos, una olla ovoide de cuello indicado, un vasito ovoide, un cuenco grande semiesférico, una fuente de casquete esférico, una quesera, una olla globular, un cuenco grande semiesférico de borde vertical y abundante fauna.

\subsection{Metales encontrados en el interior de la cueva- cámara}

Varias son las piezas metálicas recuperadas hasta el momento en el interior de la cueva de Castillejo del Bonete. Se trata de una muestra importante dada la reducida superficie excavada en el interior de la misma.

En el interior de la cueva han sido excavados por el momento dos únicos sondeos, con unas dimensiones de $2 \times 2 \mathrm{~m}$. Su objetivo fue la verificación de la potencia estratigráfica y posible uso humano de la cueva. En ellos han sido detectados 
varios estratos derivados que cubren dos claros niveles de uso antrópico, actualmente en proceso de estudio.

El primer útil metálico recuperado en estos sondeos es una larga varilla o aguja de $10 \mathrm{~cm}$ de longitud (Fig. 8, n. ${ }^{\circ}$ 2). Está asociada a un estrato derivado, arcilloso, con alto contenido de piedras calizas que han permitido la preservación excepcional de los restos en su interior. Este estrato ha tenido una movilidad reducida, según se desprende del alto grado de conservación de sus elementos. El material arqueológico asociado a esta aguja son fragmentos de cerámica de diversas formas -cuencos, fuente cazuela carenada, vasos y ollas-, algunas de ellas con superficies bruñidas. También fueron encontrados en el lugar restos de fauna -tanto carnívoros como ovicápridos-, así como restos de un enterramiento parcialmente alterado -del Individuo 6-. A esta inhumación se vinculan elementos destacables como son un aguzado punzón de hueso o un colgante elaborado con colmillo de jabalí de $11 \mathrm{~cm}$ de longitud, que presenta dos muescas triangulares en el extremo y una sección trapezoidal en la parte inferior.

La segunda pieza metálica descubierta dentro de la cueva es un punzón de sección cuadrada y $3,5 \mathrm{~cm}$ de longitud (Fig. 8, n. ${ }^{\circ} 3$ ). Está aguzado en su extremo distal y apareció asociado a la colmatación de un nivel de uso. Este estrato se encuentra sellado entre los dos niveles de

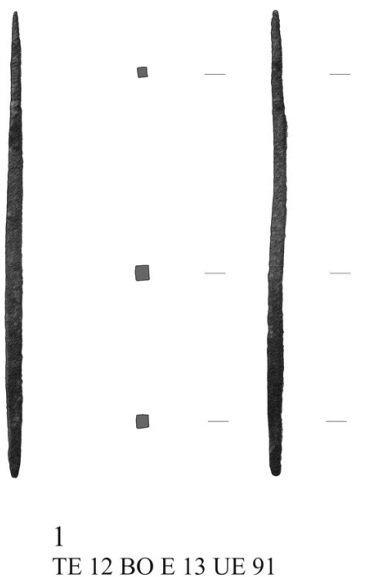

TE 12 BO E 13 UE 9

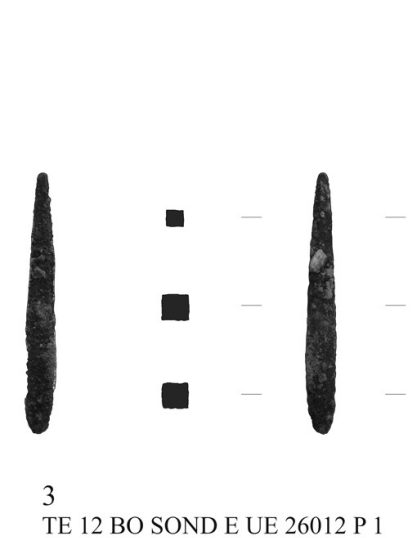

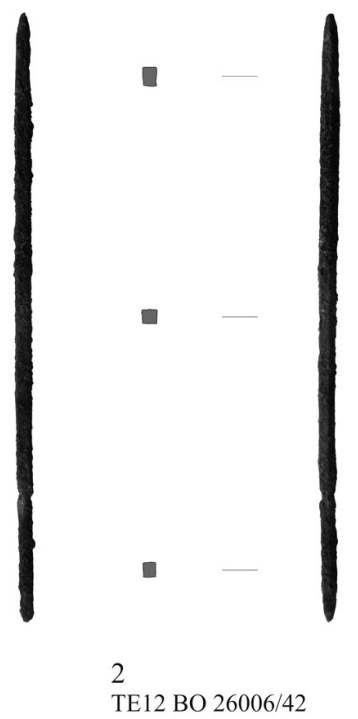

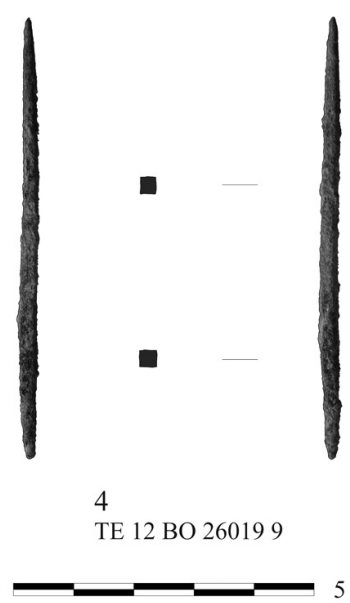

$5 \mathrm{~cm}$

FIG. 8. Punzones y agujas de Castillejo del Bonete. uso detectados, por lo que no está derivado. Es un estrato arcilloso, de tono pardo, parcialmente cortado por el nivel superior en busca de la nivelación del propio pavimento superior. Por sus características contiene un reducido número de objetos arqueológicos, pero en él se han documentado varias formas cerámicas como un vaso carenado y terminación bruñida, un cuenco semiesférico bruñido y una olla ovoide de forma indeterminada, fauna con presencia de ovicápridos, así como restos humanos sin conexión anatómica. La procedencia de esta herramienta podría haber estado relacionada con los restos humanos localizados en este estrato. 
de pequeños animales, restos humanos de varios individuos, así como unas piezas claramente suntuarias -31 cuentas de variscita-. Todos estos elementos aparecen concentrados en un espacio reducido, de $30 \times 20 \mathrm{~cm}$, con una potencia de 8 $\mathrm{cm}$ y de difícil acceso, debido a la baja cota de la bóveda de piedra en este lugar. Se ha obtenido una fecha radiocarbónica a partir del colágeno de un primer metacarpiano derecho de un individuo, con el resultado de $3870 \pm 30$ BP (Beta-350768; cf. calibraciones en Fig. 22).

El interior de la cueva ha entregado en diciembre de 2012 una cuarta pieza metálica, completa y en excelente estado de conservación. Se trata de un puñal de remaches (Fig. 3, n. ${ }^{\circ}$ 4). Se ha encontrado debajo de una laja caliza de aproximadamente $30 \mathrm{~cm}$ en su longitud máxima y dentro de una mancha de ceniza que se encuentra por el momento pendiente de excavación. La pieza conserva dos remaches y presenta otras tres perforaciones. Las dos inferiores se sitúan por debajo de la huella del enmangue, a la altura de dos leves escotaduras laterales que delimitan un ligero estrechamiento de la hoja. Sin duda se trata de una disposición atípica, ya que los puñales con tres remaches presentan una disposición triangular de las perforaciones, como la que presentan las tres perforaciones superiores de este puñal. Los dos remaches quedan excesivamente próximos y alineados con el hueco superior. Todo ello sugiere que la disposición actual de los remaches se debe a una rectificación en una configuración inicial con tres remaches.

\section{Estudio arqueometalúrgico de Castillejo del Bonete}

La investigación realizada sobre los metales del yacimiento ha combinado diferentes técnicas y equipos de análisis. Los análisis de composición elemental han sido mayoritariamente realizados con un equipo portátil de espectrometría por fluorescencia de rayos X (pXRF) INNOV-X Alpha equipado con tubo de rayos $\mathrm{X}$ con ánodo de plata, condiciones de trabajo: $35 \mathrm{kV}, 2 \mu \mathrm{A}$. Los tiempos de adquisición se fijaron en $40 \mathrm{~s}$ y los valores cuantitativos fueron calculados a partir de una calibración validada con patrones certificados. Los análisis se expresan como porcentaje en peso de cada uno de los elementos detectados. Los resultados de los elementos detectados, normalizados a $100 \%$, se recogen en la Fig. 9. En el caso de la plata $(\mathrm{Ag})$ y el antimonio ( $\mathrm{Sb}$ ) el límite de detección es $0,20 \%$, para el resto de elementos se sitúa en el 0,02\%. Los márgenes de error de los resultados son inferiores al $0,5 \%$ en el cobre $(\mathrm{Cu})$ e inferiores al 3\% en el arsénico (As).

El puñal con muescas (Fig. 3, n. ${ }^{\circ}$ 1) fue estudiado mediante Microscopía Electrónica de Barrido (SEM) con microanálisis por espectrometría de dispersión de energías de rayos X (EDS) en modo de electrones secundarios retrodispersados (BSE). Posteriormente se extrajo una muestra para su estudio metalográfico (ataque con cloruro férrico). El puñal de un remache procedente de la Tumba 4 (Fig. 3, n.o 3) fue estudiado también mediante microscopia electrónica de barrido (JEOL-1200), metalografía y microdureza (Microdurómetro AKASHI). La composición de estas dos piezas aparece en la Fig. 10.

Finalmente las muestras para metalografía y microdureza realizadas en los laboratorios del Instituto de Historia del CSIC siguieron el siguiente proceso: primero fueron embutidas en bloques de resina bi-componente autopolimerizante (metacrilato de metilo) de fraguado rápido utilizando moldes de caucho. Los bloques fueron primero devastados en húmedo utilizando cinco papeles de lija de carburo de silicio desde el tamaño de grano más grueso (P100) hasta el más fino (P1200) usando una pulidora automática PRESI Modelo Mecapol con brazo PERU y cabezal de 6 probetas. La orientación de las probetas se fue rotando $90^{\circ}$ con cada papel de lija. Posteriormente fueron pulidas empleando paños de fieltro con una solución de alúmina en suspensión $(99,98 \% \mathrm{Al})$ hasta un tamaño de grano de $0,04 \mu$. Con una velocidad de $200 \mathrm{rpm}$ y un tiempo de pulido variable. Una vez pulidas, las piezas se atacaron con solución acuosa de cloruro férrico $[60 \mathrm{ml}$ de agua destilada, $15 \mathrm{ml}$ de ácido clorhídrico $(\mathrm{HCl})$ y $5 \mathrm{~g}$ de cloruro férrico $(\mathrm{FeCl} 3)]$ durante 5 segundos y se observaron en el microscopio óptico Leica DMLM de hasta 1000x. Los análisis de microdureza se realizaron con un microdurómetro REMET HX1000 con una 


\begin{tabular}{|c|c|c|c|c|c|c|c|c|c|c|c|}
\hline Análisis & Objeto & Contexto & $\begin{array}{c}\text { Figura/ } \\
\text { Pieza }\end{array}$ & N. ${ }^{\circ}$ Inventario & $\begin{array}{r}\text { Peso } \\
(\mathrm{g})\end{array}$ & $\mathrm{Fe}$ & $\mathrm{Cu}$ & As & Ag & $\mathrm{Sb}$ & $\mathrm{Pb}$ \\
\hline PA22016 & Puñal de remaches & $\mathrm{C}$ & $\mathrm{F} 3 / 4$ & $\mathrm{TE} 12 / \mathrm{BO} / 26022 / 1$ & & - & 98,2 & 1,81 & $<0,2$ & $<0,2$ & - \\
\hline PA21545 & Punta Palmela & F & F6/1 & TE08BOD10UE6 & 3,15 & - & 97,7 & 1,62 & 0,19 & $<0,2$ & 0,48 \\
\hline PA21548 & Pedúnculo flecha & $\mathrm{D}$ & F6/4 & TE12BOC12 UE84 & 1,84 & - & 92,6 & 7,34 & $<0,2$ & $<0,2$ & 0,06 \\
\hline PA21542 & Pedúnculo flecha & DER & $\mathrm{F} 6 / 5$ & TE08BOH12UE86 & 0,9 & - & 96,9 & 3,09 & $<0,2$ & $<0,2$ & - \\
\hline PA21537 & Punzón brújula & $\mathrm{D}$ & $\mathrm{F} 4 / 3$ & TE08BOG12UE76 & 1,56 & - & 94,9 & 5,11 & $<0,2$ & $<0,2$ & - \\
\hline PA21540 & Punta flecha (rota) & $\mathrm{D}$ & $\mathrm{F} 6 / 3$ & TE08BOK5UE111 & 2,1 & - & 96,1 & 3,86 & $<0,2$ & $<0,2$ & - \\
\hline PA21541 & Palmela & $\mathrm{D}$ & $\mathrm{F} 6 / 2$ & TE08BOK3UE116 & 3,96 & - & 95,6 & 4,35 & $<0,2$ & $<0,2$ & - \\
\hline PA21544 & Punzón & D & $\mathrm{F} 4 / 5$ & TE08BOK1UE114 & 1,38 & - & 96,0 & 4,03 & $<0,2$ & $<0,2$ & - \\
\hline PA21543 & Aguja & DER & $\mathrm{F} 4 / 7$ & TE08BOF11UE85 & 0,98 & - & 97,7 & 2,27 & $<0,2$ & $<0,2$ & - \\
\hline PA21546 & Punzón & DER & $\mathrm{F} 8 / 1$ & TE12BO E13 UE 91 & 2,27 & - & 98,1 & 1,87 & $<0,2$ & $<0,2$ & - \\
\hline PA21539 & Cincel (fragmento) & DER & $\mathrm{F} 7 / 2$ & TE08BOF13UE85 & 7,12 & - & 97,9 & 2,13 & $<0,2$ & $<0,2$ & - \\
\hline PA21538 & Cincel & $\mathrm{D}$ & $\mathrm{F} 7 / 3$ & TE08BOH0UE54 & 8,35 & 0,21 & 98,3 & 1,43 & $<0,2$ & $<0,2$ & 0,05 \\
\hline PA21547 & $\begin{array}{l}\text { Fragmento metálico } \\
\text { indeterminado }\end{array}$ & DER & F7/4 & TE12BOG13-H13 UE85 & 5,38 & 0,06 & 97,0 & 2,9 & $<0,2$ & $<0,2$ & - \\
\hline PA22017 & Remache puñal 2R & $\mathrm{C}$ & $\mathrm{F} 3 / 4$ & $\mathrm{TE} 12 / \mathrm{BO} / 26022 / 2$ & & - & 97,3 & 2,67 & $<0,2$ & $<0,2$ & - \\
\hline PA22024 & Punzón & C & $\mathrm{F} 8 / 4$ & TE12BO/26019/9 & & 0,08 & 99,9 & 0 & $<0,2$ & $<0,2$ & - \\
\hline PA22025 & Punzón & $\mathrm{C}$ & $\mathrm{F} 8 / 2$ & TE12BO/26006/42 & & - & 95,8 & 3,79 & 0,27 & $<0,2$ & - \\
\hline PA22109 & Cincel (fragmento) & C & $\mathrm{F} 7 / 5$ & TE12BO UE170 1 & 7,9 & - & 97,1 & 2,88 & $<0,2$ & $<0,2$ & - \\
\hline PA22110 & Punzón & $\mathrm{C}$ & $\mathrm{F} 8 / 1$ & TE12BO 260121 & 1,67 & 0,08 & 99,8 & 0,09 & $<0,2$ & $<0,2$ & - \\
\hline
\end{tabular}

FIG. 9. Análisis XRF Valores expresados en $\%$ en peso. Contexto ( $F=$ funerario; $D=$ depositados; $D E R=$ derivados; $C=$ interior cueva; $-=$ no detectado), no se incluyen en la tabla elementos que no han sido detectados en ningún análisis como Co, $\mathrm{Ni}, \mathrm{Zn}, \mathrm{Sn}, \mathrm{Sb}$ y $\mathrm{Bi}$.

variación de carga de entre 200 y 300 g y un tiempo de incisión de $15 \mathrm{~s}$.

Los análisis de isótopos de plomo se realizaron a partir de una muestra extraída mediante limadura de la superficie del metal en el Servicio de Geocronología y Geoquímica (sGiker) de la Universidad del País Vasco. Desde 2010 se utiliza un espectrómetro de masas de alta resolución y multicolección con fuente de plasma acoplado inductivamente (MC-ICP-MS Neptune). Esta técnica permite analizar muestras más pequeñas y corregir satisfactoriamente el fraccionamiento instrumental mediante la adición de Tl, proporcionando precisión, exactitud y reproducibilidad comparables a los métodos complejos de doble o triple Spike con espectrómetros de fuente de

\begin{tabular}{|c|l|l|l|c|c|c|c|c|}
\hline Análisis & \multicolumn{1}{|c|}{ Objeto } & Lám./Pieza & \multicolumn{1}{|c|}{ N. ${ }^{\circ}$ Inventario } & Cu & Std & As & Std & Otros \\
\hline SEM & Puñal & $1 / 1$ & TE05BOF12 UE76 & 97,0 & 0,51 & 2,94 & 0,42 & \\
\hline SEM & Puñal & $1 / 3 \mathrm{I}$ & TE04BOUC15 Tumba4 & 96,1 & 0,51 & 3,88 & 0,50 & \\
\hline SEM & Remache puñal & 173 & TE04BOUC15 Tumba4 & 96,3 & 0,32 & 3,75 & 0,46 & Bismuto \\
\hline
\end{tabular}

FIG. 10. Análisis elemental obtenido en SEM. Valores expresados en \% en peso; la precisión en el contenido de arsénico es inferior al señalado para los análisis XRF, incorporándose la desviación estándar (Std). 
ionización térmica (TIMS) como el empleado en el mismo laboratorio en fechas anteriores. Los protocolos de tratamiento y procesado seguidos en el laboratorio son los descritos en Chernysev et al. (2007).

\subsection{Análisis elemental}

El principal rasgo de los metales de Castillejo del Bonete es su elevada tasa de arsénico. Salvo en dos punzones de la cueva, el resto de los objetos presenta contenidos superiores al $1 \%$ de As, siendo la media del conjunto de $2,94 \%$ de As. Tasas medias tan elevadas sólo están documentadas en algunos yacimientos del SE como Almizaraque o El Argar (Montero Ruiz, 1999: 346), alejándose de los datos disponibles para los metales de la Edad del Bronce en la Meseta Sur, cuya media nunca supera el 1,5\% de As (Fernández-Posse et al., 1999: 235). En nuestra opinión, el contenido medio de arsénico se puede relacionar con el tipo de materia prima utilizado, siendo en este caso, además, un indicador indirecto de que se trata de una metalurgia con baja tasa de reciclado de metal ya que, al ser el arsénico un elemento muy volátil, este se pierde paulatinamente en los distintos procesos térmicos a los que puede verse sometido el metal.

El patrón de elementos minoritarios parece bastante similar en los metales analizados, pero dadas las limitaciones en la cuantificación de los contenidos de plata y antimonio no podemos establecer pautas comparativas con análisis previos realizados y publicados por el Proyecto de Arqueometalurgia de la Península Ibérica (Rovira et al., 1997). Sin embargo, debemos señalar que la punta Palmela PA21545 y el punzón PA22025 se diferencian del resto de objetos de este yacimiento al presentar un contenido elevado de plata $(0,19 \%$ y $0,27 \%$ de $\mathrm{Ag}$ respectivamente); además la Palmela presenta también una tasa elevada de plomo $(0,48 \%$ de $\mathrm{Pb})$. Esta Palmela es la que se depositó sobre la Tumba 4 (Fig. 6, n. ${ }^{\circ} 1$ ). No podemos descartar que pueda tener una composición similar a los puñales de la sepultura ya que uno de ellos no ha sido analizado y el análisis por SEM del otro (Fig. 3, n. ${ }^{\circ}$ 3) no permite cuantificar elementos minoritarios. Más adelante, con el resultado de análisis de isótopos de plomo podremos valorar cuestiones sobre la homogeneidad o no de la procedencia del metal en el Castillejo del Bonete.

\subsection{Metalografias}

En cuanto a las metalografías se han podido estudiar 3 puñales, 2 remaches y 1 fragmento del cuerpo de un cincel.

- Puñal de lengüeta con remache TE04BOUC15 Tumba 4 (Fig. 3, n. ${ }^{\circ}$ 3): la microestructura de la matriz metálica está formada por granos poliédricos que muestran cierto maclado, algunos con tensiones internas (Fig. 13). Esto indica que la pieza ha sido trabajada en frío tras ser colada, posteriormente recocida y ha recibido un ulterior trabajo de acabado o de uso. La microestructura es de pequeño grano, lo cual indica que el recocido no fue a temperatura muy alta, y no se dejó la pieza mucho tiempo a esta temperatura, lo que provocó un grano pequeño. El trabajo de forja final no fue muy intenso (Fig. 11).

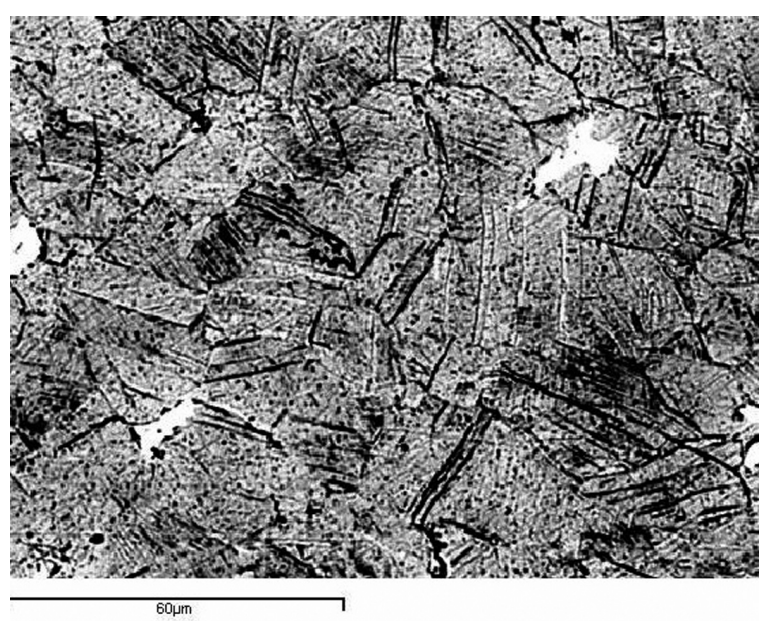

FIG. 11. Fotografía realizada con microscopio electrónico de barrido JEOL1200 al puñal de un remache (Fig. 3, n.o 3). La imagen revela la forma de los cristales (de coloración clara) y la distribución de estos en una matriz de granos maclados y con tensiones internas. Imagen de la pieza sin atacar (fotografía de J. Simón Arias). 


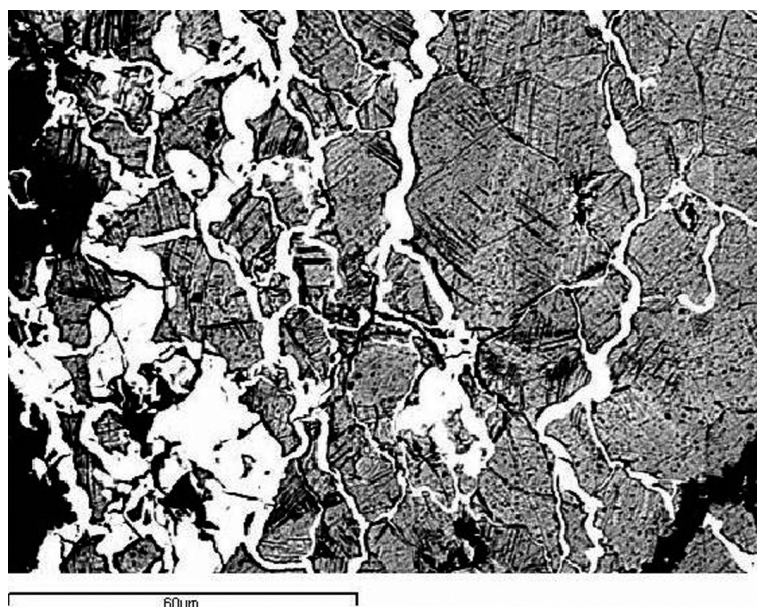

FIG. 12. Fotografia realizada con microscopio electrónico de barrido JEOL1200 al remache del puñal encontrado en la Tumba 4 (Fig. 3, n.o 3). La imagen muestra precipitados intergranulares de coloración más clara (más ricos en arsénico), así como la matriz metálica con granos maclados y con tensiones internas (fotografía de J. Simón Arias).

- Remache del puñal te04Bouc15 Tumba 4 (Fig. 3, n. ${ }^{\circ}$ 3): la microestructura de la matriz metálica de la muestra es en todo semejante a la del puñal. Se trata de un metal fundido que se ha moldeado y ha solidificado formando una solución sólida que se ha trabajado en frío, se ha sometido al tratamiento térmico de recocido y se ha finalizado volviendo a trabajar en frío (Fig. 12).

- Puñal con muescas Te05/Bo/F12/UE76 (Fig. 3 , n. ${ }^{\circ}$ 1): la muestra procede de la zona del talón y por tanto no representa el filo. La estructura metalográfica del puñal es monofásica con algunos granos más ricos en arsénico (Fig. 13). La forma inicial se realizó mediante colada y tuvo un intenso trabajado en frío final.

- Puñal de 3 remaches TE12/Bo/26022/1 (Fig. 3 , n. $\left.{ }^{\circ} 4\right)$ : la metalografía se practicó en la zona central del filo. El puñal fue elaborado a partir de la deformación plástica, mediante la forja, de una pieza inicialmente colada en molde. La colada de cobre, al solidificar en el molde, desarrolló una estructura dendrítica que puede intuirse en las bandas horizontales anaranjadas y amarillentas de

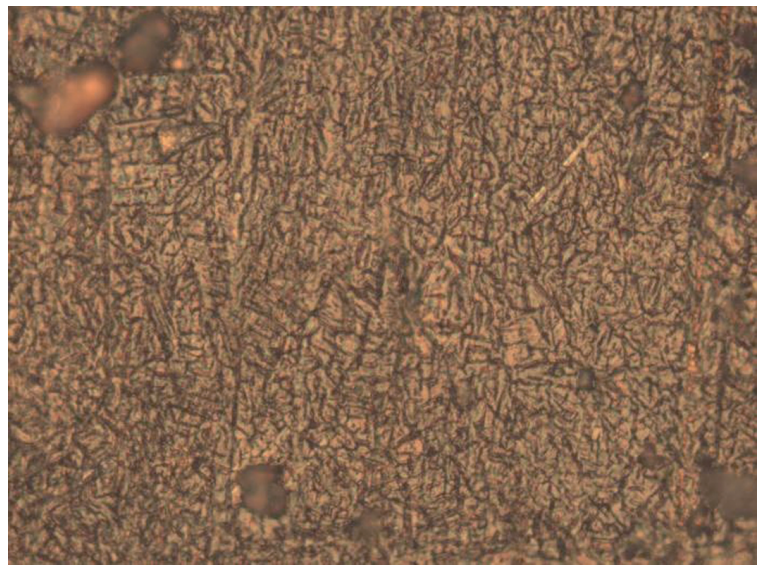

FIG. 13. Fotografía de microscopía óptica del cuchillo dentado (Fig. 3, n.o 1), pulido y atacado con cloruro férrico (X50). La imagen revela una estructura monofásica a formada por pequeños granos poliédricos deformados y con un elevado número de lineas paralelas (maclas de deformación). Esta estructura del núcleo metálico revela que ha sufrido una intensa fase de trabajado en frio del metal (fotografía de A. Gómez Morón).

la pieza. A 100 magnificaciones puede observarse la estructura 'hojaldrada' propia del trabajo de forja en frío (Fig. 14a). No se observa ninguna evidencia de recocido o exposición de la pieza al calor. A una mayor magnificación (200x) se observa que las bandas generadas por la forja son más finas en el filo del puñal (Fig. 14b), lo que indica un trabajo ligeramente más intenso en el filo que en la zona interior. Las inclusiones y pequeñas porosidades de la colada también aparecen deformadas horizontalmente como fruto del trabajo de forja.

- Remache del puñal TE12/BO/26022/1 (Fig. 3 , n. ${ }^{\circ} 4$ ): el remache, de sección cuadrangular, fue probablemente elaborado a partir de una barra de metal martilleada hasta conseguir la forma deseada. La microestructura que se observa es la propia de una forja en frío sin evidencias de recocido. La estructura dendrítica resultante del enfriamiento de la colada en un molde parece todavía intuirse aunque ésta ha quedado deformada en bandas por el trabajo de forja. A 50x se observa que la pieza fue probablemente martilleada por los cuatro lados ya que las bandas se disponen siguiendo una 

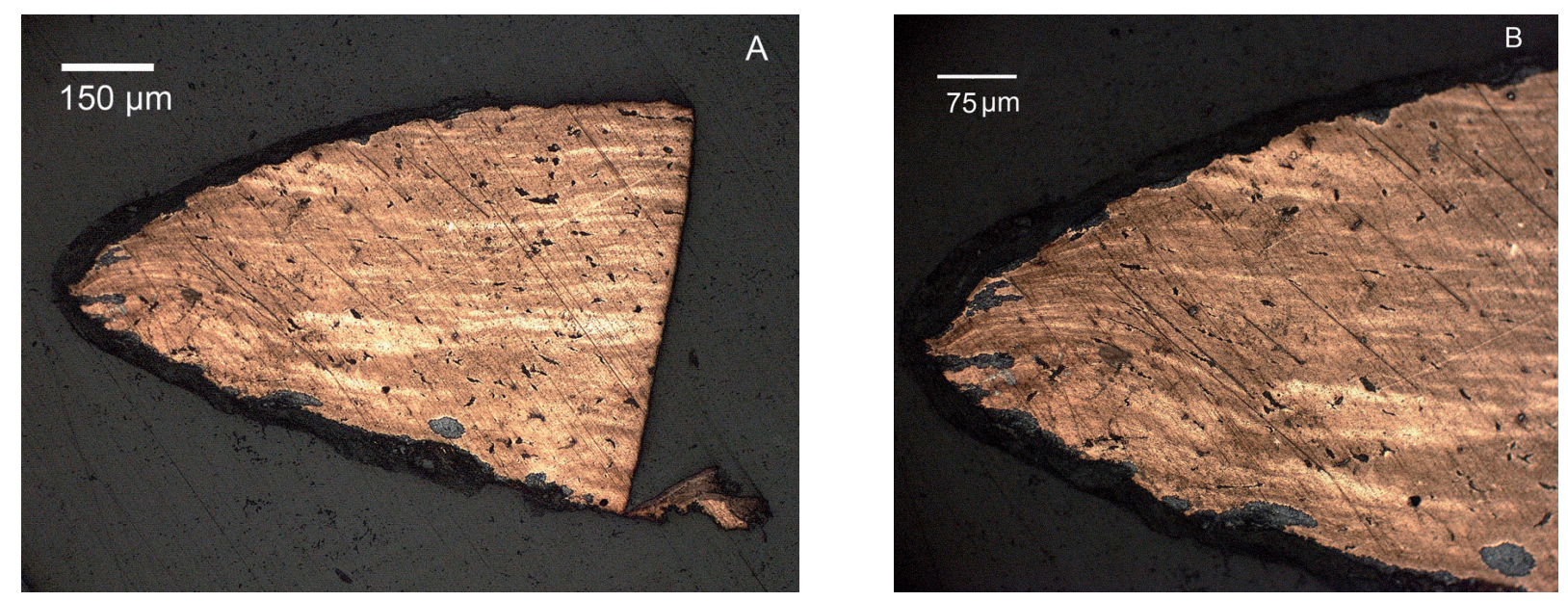

FIG. 14. Metalografía del puñal de remaches TE12/BO/26022/1 (Fig. 3, n.o 4) que señala su manufactura con la cadena corta de trabajo (fundición + forja en frio): A) vista general a 1000x; B) detalle del filo a 200x.

trayectoria transversal al punto desde el que se aplica la forja (Fig. 15). Las medidas de microdureza también revelan que la intensidad de la forja no fue excesiva, ya que los valores de dureza Vickers tampoco son muy altos -con una media de 137 HV [7,9 Std.]-.

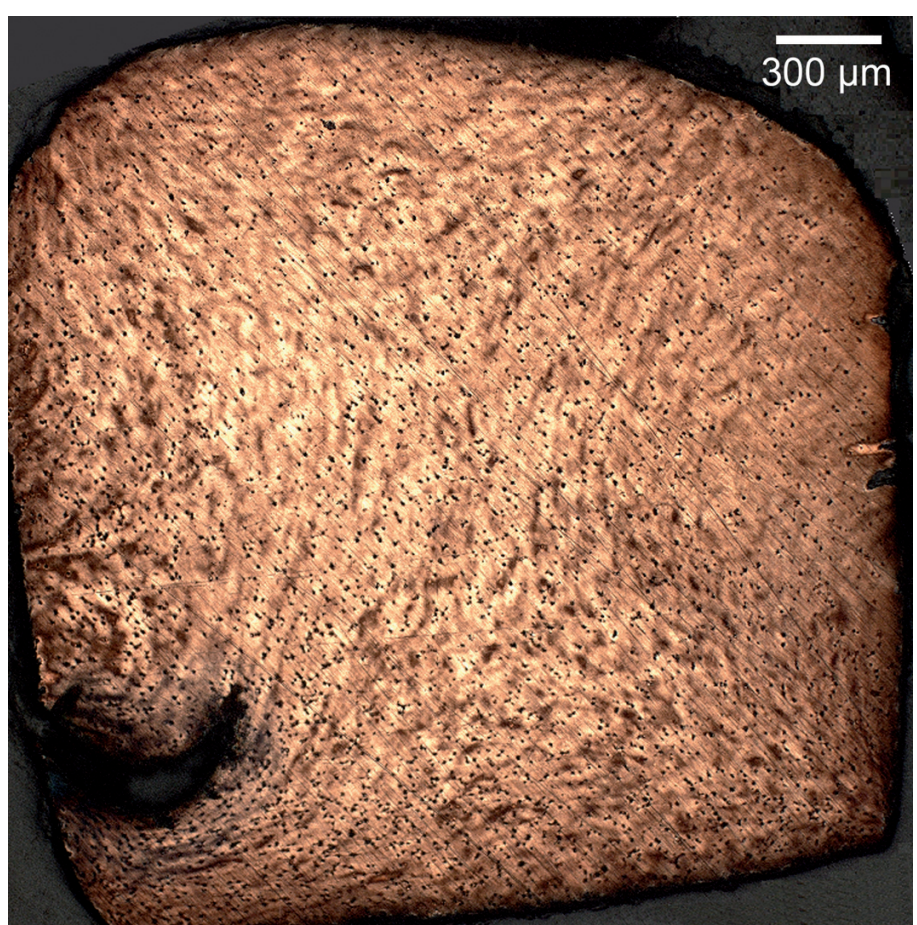

FIG. 15. Metalografía del puñal de remaches TE12/BO/26022/1 (Fig. 3, n.o 4) con estructura de forja en frío (50x) realizada por los cuatro lados.
- Fragmento de cincel TE12/BO/170/1 (Fig. 7, n. ${ }^{\circ}$ 5): la metalografía se ha realizado en la sección completa de una de las fracturas. El cincel muestra una microestructura de deformación por forja, sin que se aprecien signos de recocido. La estructura dendrítica remanente ha quedado deformada por el efecto de la forja formando bandas transversales al punto desde el que se ejerce la presión, que fue por los 4 lados de la pieza. El trabajo de forja no debió de ser muy intenso ya que aún se aprecian de forma bastante evidente indicios de la estructura dendrítica a 100x (Fig. 16a). Sin embargo, a mayor magnificación (500x) se detecta, en el filo de uno de los lados largos de la pieza, una mayor deformación mecánica tanto por el mayor aplastamiento de las inclusiones y porosidades como en la gran cantidad de líneas de estrés y bandas de deslizamiento, algo que no se observa en el interior del cincel (Fig. 16b).

Aunque los tres puñales acaban con forja en frío de los filos, en el procedente de la Tumba 4 tenemos desarrollada la 


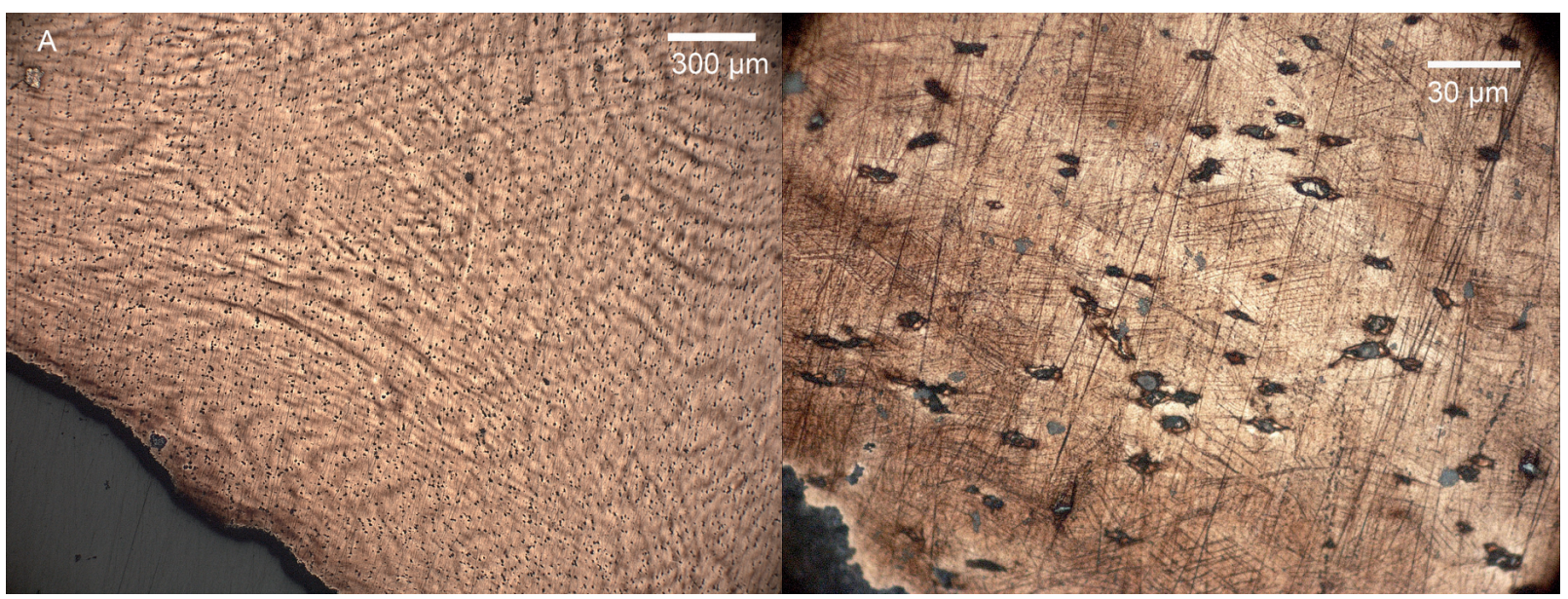

FIG. 16. Metalografía de la sección del cincel TE12/BO/170/1 (Fig. 7, n.o 5) con estructura de fundición y deformación mediante forja en frío de la estructura dendritica. A) Vista general a 100x; B) Detalle de uno de los bordes (500x).

cadena de trabajo larga, que incorpora el tratamiento de recocido, mientras en los otros dos no se ha detectado esa tarea previa a la forja. La cadena corta es típica del Calcolítico, apareciendo con mayor frecuencia la cadena larga conforme avanzamos en la Edad del Bronce (Rovira y Gómez Ramos, 2003: 170), sin que desaparezca la cadena corta.

En cuanto a los remaches, lo habitual es que se configuren mediante un trabajo de forja y que se produzca una deformación final para su ajuste definitivo en la zona de la cabeza. En ambos casos presentan la misma secuencia de trabajo que la encontrada en los puñales a los que están asociados, es decir, cadena larga para el puñal de lengüeta y cadena corta en el puñal de remaches.

Tanto el puñal de lengüeta con remache (TE04/BO/UC15 Tumba 4) como el puñal de 3 remaches de la cueva (TE12/BO/26022/1) cuentan con mediciones de microdureza en el filo y en el remache. En el filo las medidas realizadas en los bordes e interior muestran claramente el proceso de endurecimiento por forja en ambos puñales, siendo el núcleo metálico algo más blando.

La dureza media de estas piezas se encuentra dentro de los valores medios de los datos disponibles hoy día (Fig. 18). La dureza está en función de dos parámetros principales: la composición y la técnica de manufactura -en este caso, la intensidad de la forja final-. Piezas con una mayor proporción de elementos acompañando al cobre ofrecerán mayor dureza con el mismo tipo de trabajo. El trabajo de recocido sufrido por el puñal de lengüeta ha incidido en que su dureza media sea inferior, a pesar de ser una pieza con mayor contenido en arsénico (Fig. 17) que el otro puñal. Además la forja final no fue muy intensa. En los remaches no se aprecia una clara diferenciación entre las medidas del borde y el interior. Los valores de microdureza de los remaches son muy semejantes en ambos casos a pesar de las diferencias de composición y técnica de trabajo.

\begin{tabular}{|l|l|l|l|l|}
\hline & \multicolumn{2}{|c|}{ Puñal lengüeta } & \multicolumn{2}{c|}{ Puñal 3R } \\
\hline & \multicolumn{1}{|c}{ Filo } & \multicolumn{1}{c|}{ Remache } & \multicolumn{1}{c|}{ Filo } & Remache \\
\hline Borde filo & $150 \mathrm{HV}$ & $132 \mathrm{HV}$ & $180 \mathrm{HV}$ & $139 \mathrm{HV}$ \\
\hline Centro & $115 \mathrm{HV}$ & $141 \mathrm{HV}$ & $150 \mathrm{HV}$ & $137 \mathrm{HV}$ \\
\hline As $\%$ & 3,88 & 3,75 & 1,81 & 2,67 \\
\hline Cadena & $\mathrm{F}+\mathrm{FF}+\mathrm{R}+\mathrm{FF}$ & $\mathrm{F}+\mathrm{FF}+\mathrm{R}+\mathrm{FF}$ & $\mathrm{F}+\mathrm{FF}$ & $\mathrm{F}+\mathrm{FF}$ \\
\hline
\end{tabular}

FIG. 17. Comparación de valores de microdureza en relación a la técnica de manufactura ( $F=$ fundición; $F F=$ forja en frio; $R=$ recocido) y contenido de arsénico. 


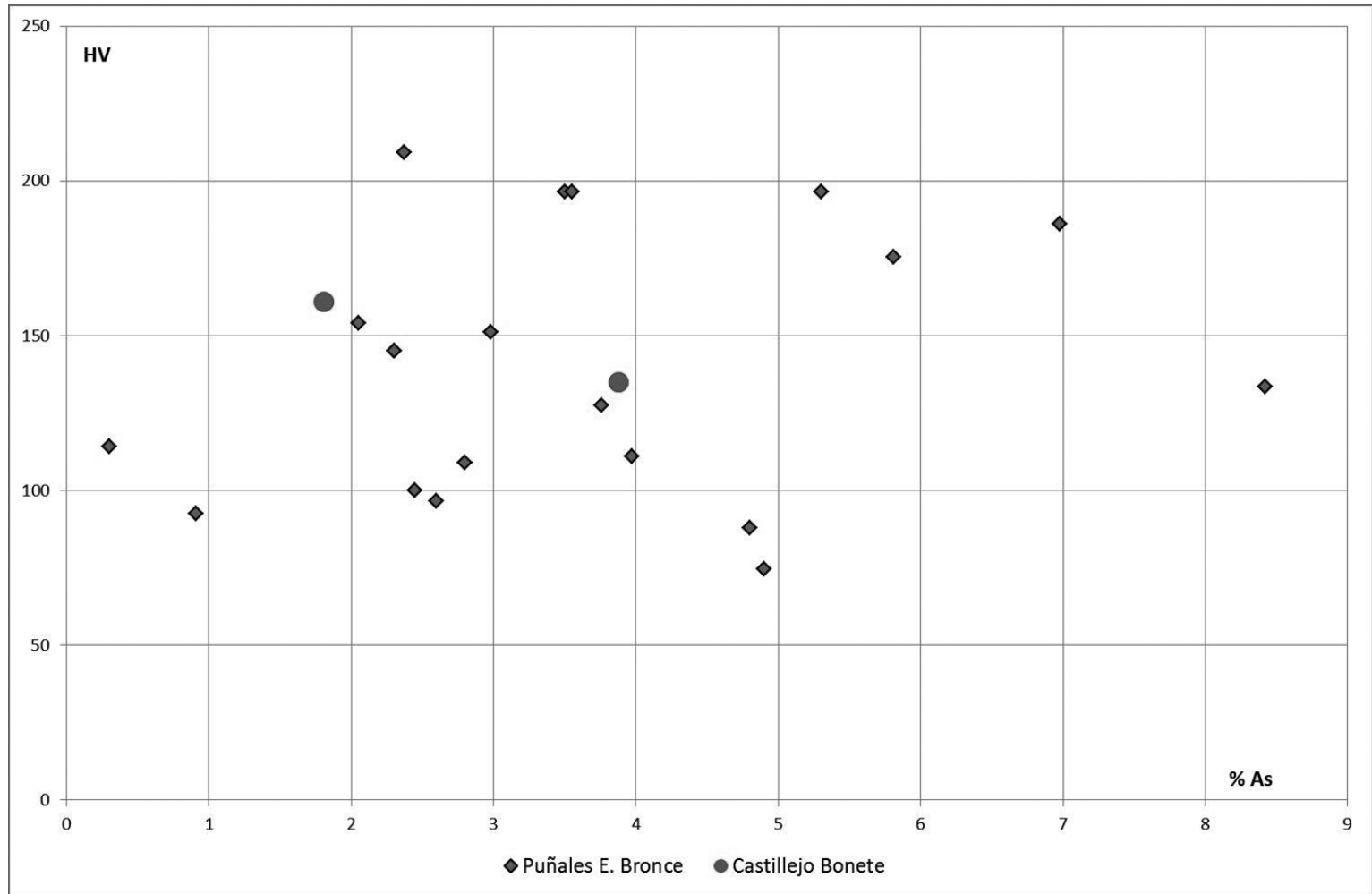

FIG. 18. Comparación del valor medio de microdureza de los puñales de Castillejo de Bonete en relación a otros puñales de cobre arsenicado del Calcolitico y Edad de Bronce de la Península Ibérica.

\begin{tabular}{|c|c|c|c|c|c|c|c|c|}
\hline Yacimiento & Objeto & Inventario & $\begin{array}{c}208 \mathrm{~Pb} / \\
206 \mathrm{~Pb}\end{array}$ & $\begin{array}{c}207 \mathrm{~Pb} / \\
206 \mathrm{~Pb}\end{array}$ & $\begin{array}{l}206 \mathrm{~Pb} / \\
204 \mathrm{~Pb}\end{array}$ & $\begin{array}{l}207 \mathrm{~Pb} / \\
204 \mathrm{~Pb}\end{array}$ & $\begin{array}{l}208 \mathrm{~Pb} / \\
204 \mathrm{~Pb}\end{array}$ & As $\%$ \\
\hline El Acequión & Hacha plana & PA0717 & 2,02773 & 0,82402 & 19,069 & 15,7133 & 38,6667 & 0,53 \\
\hline El Acequión & Hacha plana & PA0719 & 2,07555 & 0,84263 & 18,587 & 15,662 & 38,5782 & 0,74 \\
\hline El Acequión & Puñal & AA1471 & 2,08919 & 0,84394 & 18,5784 & 15,679 & 38,8138 & 1,63 \\
\hline El Acequión & Punzón & PA0201 & 2,0399 & 0,8235 & 19,0614 & 15,6962 & 38,8825 & 0,43 \\
\hline El Acequión & Hacha plana & PA0718 & 2,0963 & 0,85174 & 18,4339 & 15,701 & 38,6431 & 2,26 \\
\hline Castillejo Bonete & Puñal 2R & PA22016 & 2,06165 & 0,83694 & 18,7542 & 15,6961 & 38,6646 & 1,81 \\
\hline Castillejo Bonete & Punzón & PA22024 & 2,09858 & 0,85149 & 18,4083 & 15,6746 & 38,6313 & - \\
\hline Castillejo Bonete & Cincel & PA22109 & 2,08807 & 0,84777 & 18,499 & 15,683 & 38,6273 & 2,88 \\
\hline Castillejo Bonete & Punzón & PA22110 & 2,10019 & 0,85387 & 18,3622 & 15,679 & 38,5641 & 0,09 \\
\hline Castillejo Bonete & Cincel & PA21538 & 2,09067 & 0,85173 & 18,3735 & 15,6493 & 38,4131 & 1,43 \\
\hline Castillejo Bonete & Punzón & PA21541 & 2,10199 & 0,85584 & 18,2796 & 15,6443 & 38,4235 & 4,35 \\
\hline Castillejo Bonete & Flecha & PA21542 & 2,0996 & 0,85532 & 18,2852 & 15,6397 & 38,3917 & 3,09 \\
\hline Castillejo Bonete & Flecha & PA21548 & 2,10114 & 0,85508 & 18,2917 & 15,641 & 38,4335 & 7,34 \\
\hline
\end{tabular}

FIG. 19. Resultados de los análisis de isótopos de plomo (MC-ICP-MS) realizados por el servicio de Geocronología de la UPV, junto al contenido de arsénico obtenido por XRF (- = no detectado); los análisis XRF de El Acequión se encuentran publicados en Rovira et al., 1997: 19-22. 


\subsection{Análisis de isótopos de plomo}

Se ha iniciado un estudio basado en los isótopos de plomo para conocer la procedencia del metal utilizado en los objetos recuperados en Castillejo del Bonete. Inicialmente hemos seleccionado 8 muestras. Se han elegido piezas con distinto contenido de arsénico, ya que es el único elemento que permite diferenciar grupos por composición. Los valores se recogen en la Fig. 19.

Se han incorporado a este estudio datos inéditos de El Acequión (Albacete) para propiciar una perspectiva comparativa sobre la procedencia del metal en la Edad del Bronce con los datos disponibles del área argárica.

Los materiales de Castillejo del Bonete pueden agruparse aparentemente en dos grupos claramente diferenciados a partir de valores superiores o inferiores a 38,50 en la ratio ${ }^{208} \mathrm{~Pb} /{ }^{204} \mathrm{~Pb}$, y a 15,66 en la ratio ${ }^{207} \mathrm{~Pb} /{ }^{204} \mathrm{~Pb}$ (Fig. 20). El grupo 1 concentra los contenidos más elevados de arsénico y se relaciona directamente con las minas del distrito de Linares, incluida la mina de cobre Polígono del termino de Baños de la Encina (Hunt et al., 2011). Se aprecia que el campo isotópico de la mina de cobre José Palacios también en Bańos de la Encina queda separado de ambos grupos de metales y por tanto no hay relación de procedencia posible con ninguno de ellos. Únicamente el cincel PA21538, con 1,48\% de As, presenta una localización externa al área definida en el campo isotópico de Linares cuando observamos su posición en otras ratios (Fig. 21), por lo que la procedencia no puede atribuirse como en el resto del grupo a esta zona minera.

El segundo grupo presenta una distribución más heterogénea cuando se observa su distribución en la Fig. 21. Los dos punzones no arsenicados mantienen una posición relativa próxima entre sí, lo que podría sugerir un mismo origen,

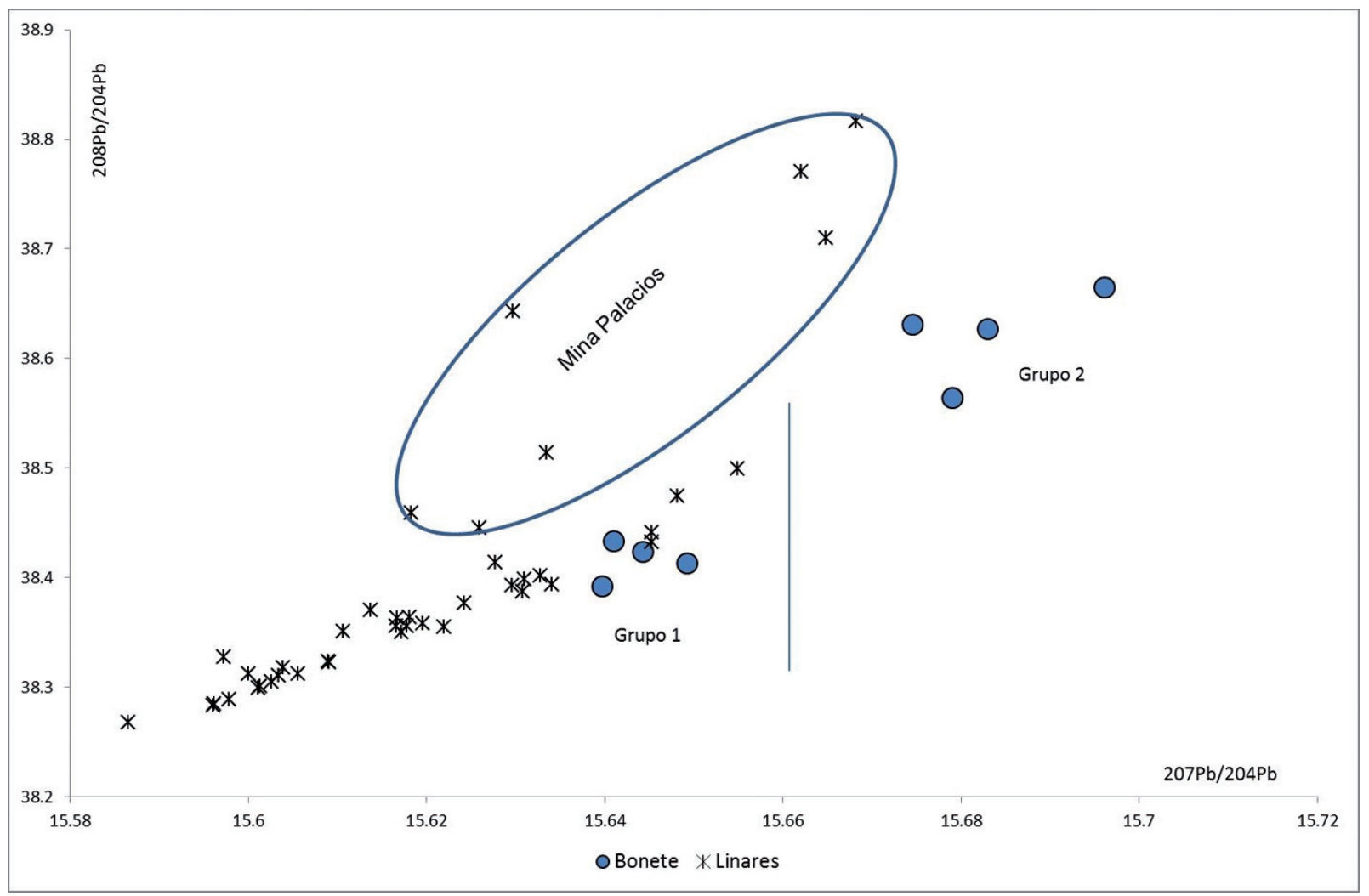

FIG. 20. Gráfica con la representación de ratios isotópicas de los metales de Castillejo de Bonete en relación a los minerales del área de Linares; se observan las dos agrupaciones materiales. 

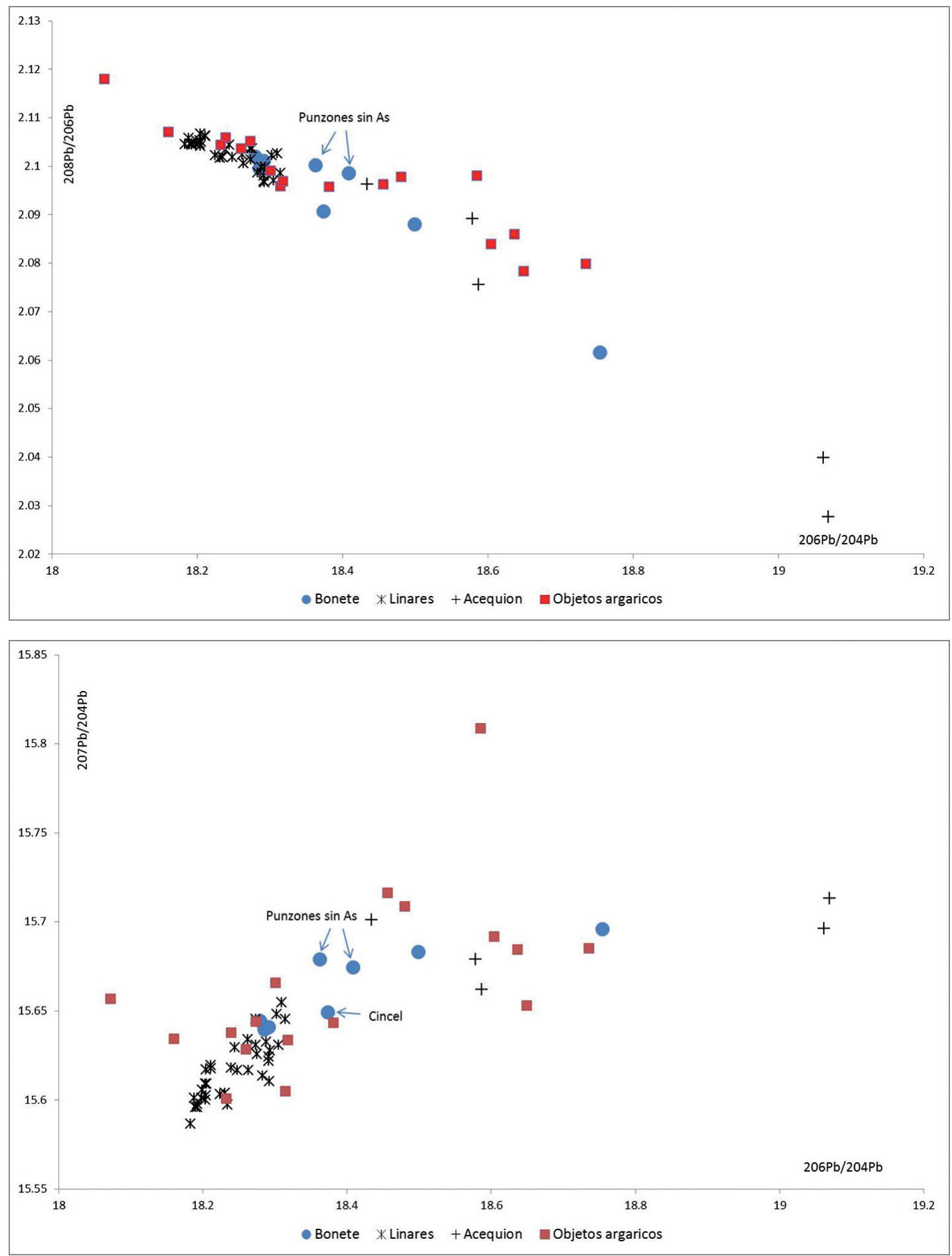

FIG. 21. Gráficas en espejo ( Bonete y de El Acequión en relación a los minerales de Linares y a los metales argáricos publicados; se señala la posición de los cobres sin arsénico de Castillejo de Bonete. 
aunque sin que podamos concretarlo por el momento. El puñal de remaches ocupa una posición alejada respecto al resto de piezas siendo la única con una ratio ${ }^{208} \mathrm{~Pb} / 206 \mathrm{~Pb}$ inferior al valor de 2,08. No tenemos ninguna referencia geológica que pueda concordar en

\begin{tabular}{|c|c|c|c|c|}
\hline Castillejo del Bonete & Ref. Lab. & Edad ${ }^{1} C^{14} B P$ & cal AC (10) & cal AC (2б) \\
\hline Tumba 4 & Rome-1687 & $3720 \pm 70 \mathrm{C}^{14}$ вр & 2271-1984 cal BC & 2340-1921 cal вс \\
\hline Interior cueva & Beta-350768 & $3870 \pm 30 \mathrm{C}^{14} \mathrm{BP}$ & $2456-2293 \mathrm{cal} \mathrm{BC}$ & 2465-2211 cal вс \\
\hline
\end{tabular}

FIG. 22. Dataciones de Castillejo del Bonete (Terrinches, Ciudad Real). La calibración de las fechas por radiocarbono se ha realizado mediante el programa OxCal 4.2.3 (Bronk Ramsey, 2009), utilizando la curva IntCal13 (Reimer et al., 2013).

todas las ratios con estas

piezas del grupo 2, aunque algunas mineralizaciones de Sierra Morena se encuentran próximas.

La comparación de las muestras de Castillejo del Bonete con el resto de materiales de la Edad del Bronce disponibles, es decir, las muestras argaricas publicadas por Stos-Gale et al. (1999) y las inéditas de El Acequión, permite observar que ninguna de ellas presenta valores similares para poder argumentar un origen común. Este panorama de diversidad de uso de mineralizaciones que ya habíamos propuesto (Montero Ruiz y MurilloBarroso, 2010) parece ir confirmándose con los nuevos datos ahora publicados.

\section{Conclusiones}

En Castillejo del Bonete resulta notable la cantidad de útiles metálicos recuperados hasta la fecha -25- depositados dentro de tumbas o en pequeños recintos, o bien localizados en posición derivada debido a las reformas sucedidas en este complejo arquitectónico monumental. Es de señalar que, hasta el momento, no se ha documentado ninguna evidencia de fundición o actividad metalúrgica en este lugar. Los útiles metálicos identificados responden a los tipos básicos de la metalurgia del Calcolítico y de la Edad del Bronce, salvo por la ausencia de adornos de cobre, sierras y hachas, aunque hay ciertos rasgos tipológicos y tecnológicos que señalan que el yacimiento no perduró hasta fases avanzadas del Bronce. La datación disponible de la Tumba 4 nos sitúa en el último tercio del III milenio cal AC, mientras que la fecha en el interior de la cueva podría ser ligeramente anterior, correspondiendo al tercer cuarto del III milenio cal AC, es decir, en la transición Calcolítico/Edad del Bronce (Fig. 22).

A pesar del elevado número de objetos metálicos encontrados no se han registrado tipos destinados al adorno personal (sí han sido encontrados adornos no metálicos, como es el caso de 31 cuentas de collar de piedras verdes). La ausencia de adornos metálicos puede responder a una cuestión cronológica, dado que los primeros manufacturados en cobre se fechan en el área argárica a partir del $1900 \mathrm{cal} \mathrm{AC}^{5}$. Por ello, la ausencia hasta el momento de adornos metálicos en Castillejo del Bonete puede ser un indicio sobre el uso de este monumento en fechas antiguas, y no avanzadas, de la Prehistoria reciente. Y más teniendo en cuenta que los adornos se vinculan mayoritariamente a los ajuares de sepulturas.

Respecto a las puntas de flecha llama la atención la uniformidad tipológica, al no apreciarse otras clases diferentes de las de tipo Palmela, como podrían ser las de pedúnculo y aletas, encontradas en otros yacimientos relativamente próximos o supuestamente contemporáneos. Así, aunque las puntas Palmela perduran durante la fase II de El Acequión y coexisten con las de aletas (transición entre III y II milenio cal AC), en la Morra del Quintanar ya aparecen las puntas con aletas en la fase I de este yacimiento y con cronologías del último cuarto del III milenio cal. AC (Fernández Miranda et al., 1996: 30).

En el caso de los puñales nos encontramos con rasgos novedosos como la incorporación de

${ }^{5}$ Costa, M. E.; García Sanjuán, L.; Montero, I. y Murillo-Barroso, M.: "The role of metal productions in the ideology of Early Bronze Age Societies (c. 2200-1500 cal ANE) in Southern Iberia”. En Pang, R. (ed.): Making Metals and Moulding Society: a Global Perspective on the Emergence of Bronze Age Social Complexity. London: Oxbow, en prensa. 
remaches - no hay puñales de remaches en el Calcolítico-. Tenemos dos casos de transición tipológica con una forma mixta de enmangue -lengüeta y remache-. Una de las dataciones se relaciona precisamente con uno de estos puñales de inicios de la Edad del Bronce. Brandherm (2003: 170) atribuye el comienzo del desarrollo de estas formas mixtas ya a la fase antigua del Bronce inicial, lo que en su terminología correspondería a la cronología propuesta para las piezas del Castillejo de Bonete. Posteriormente predominan los puñales con zona de enmangue de forma curva o trapezoidal con dos o más remaches en disposición paralela. En este sentido el puñal de remaches representaría la tipología más evolucionada dentro de los metales del yacimiento.

De los punzones y cinceles no podemos decir mucho desde el punto de vista cronológico. Únicamente la pieza que vinculamos con los llamados punzones brújula por su engrosamiento central podría indicar un rasgo de cierta modernidad dentro de la Edad del Bronce, pero esta clase de piezas está bien documentada en estos primeros momentos de la Edad del Bronce -transición III/II milenio cal AC-; en cualquier caso, tipológicamente este objeto es atípico.

En cuanto a los aspectos tecnológicos de manufactura, de las 4 piezas metalografiadas sólo en una hemos detectado la cadena larga con uso del recocido. Aunque la muestra es escasa parece indicar que todavía no se ha alcanzado el predominio de cadena larga en la manufactura de objetos. Esto sólo se conseguirá en momentos avanzados de la Edad del Bronce. Este aspecto colocaría a la metalurgia del yacimiento dentro del modelo de inicios de la Edad del Bronce.

La última cuestión cronológica a valorar es la ausencia de aleación con estaño. Aunque no está bien delimitada su aparición en la Meseta Sur, los datos disponibles del área argárica y del so peninsular indican que el bronce es un elemento tardío en sus desarrollos, posterior al $1800 \mathrm{cal} \mathrm{AC}$. De nuevo la información de los metales avala una cronología antigua dentro de la Edad del Bronce en el uso u ocupación de Castillejo del Bonete.

La amortización del preciado metal enterrado junto a los difuntos sobresale aún más si consideramos que esta zona no es metalífera y que tanto los útiles metálicos como la materia prima para su elaboración hubieron de llegar a esta zona a través de los corredores naturales de paso usados como vías de comunicación ${ }^{6}$.

$\mathrm{El}$ análisis de isótopos de plomo sugiere que una parte del metal procede del área de Linares, especialmente los elementos con mayor contenido de arsénico. La distancia entre ambas zonas es de aproximadamente $125 \mathrm{~km}$. El resto de metales parecen tener otras procedencias aún sin precisar, aunque claramente pueden descartarse las minas del Valle de la Alcudia y de las provincias de Murcia y Almería.

Un último aspecto a comentar se refiere a la funcionalidad del yacimiento. La presencia de algunas de las piezas metálicas -como los cinceles-, por su carácter, podría reflejar una ocupación doméstica del lugar. Sin embargo, si atendemos a las pautas de deposición del SE -donde ni las puntas de flecha ni los cinceles forman parte de los ajuares funerarios de la Edad del Bronce, pero sí lo hacen durante el Calcolítico-, la presencia de cinceles en el yacimiento puede suponer otro rasgo arcaizante relacionable con otros indicios como son las propias arquitecturas del monumento, el collar de piedras verdes o la industria lítica encontrada.

La presencia de útiles fragmentados y desgastados por uso -además de otros indicios arqueológicos cuya exposición excede el marco de este trabajo- parecen estar indicando que Castillejo del Bonete no fue sólo un depósito funerario de carácter estático, sino un lugar complejo dotado de una fuerte carga simbólica en el cual fueron celebrados rituales que ahora, con el avance de esta investigación aún inconclusa, empiezan a ser desvelados.

El hallazgo de restos de fauna aquí consumida o depositada, así como el hallazgo de vasos cerámicos en el lugar, parecen apuntar hacia la existencia de prácticas sociales de comensalidad relacionadas con el ritual funerario. Un ritual en el cual la consumición de determinadas bebidas y animales, junto con la amortización de los preciados metales como elementos de exhibición y reforzamiento de la asimetría social, servirían para poner de manifiesto ante la comunidad el poder y la riqueza de

\footnotetext{
${ }^{6}$ Benítez de Lugo: op. cit. n. 2.
} 
los dirigentes de los poblados próximos, que de esta forma, a través del ritual funerario, demostrarían su preeminencia social, económica y política, legitimando su poder (Aranda, 2011: 263-265 y Aranda et al., 2011).

\section{Bibliografía}

ARANDA, G. (2011): "Nuevos actores para viejos escenarios. La sociedad argárica". En Memorial Luis Siret. I Congreso de Prehistoria de Andalucía. La tutela del patrimonio prehistórico. Sevilla: Junta de Andalucía, pp. 249-270.

Aranda, G.; Montón-Subías, S. y SÁnchez RomeRO, M. (eds.) (2011): Guess who's coming to dinner. Feasting rituals in the Prehistoric Societies of Europe and the Near East. Oxford: Oxbow Books.

Benítez de Lugo, L.; Mejías, M.; López GutiérRez, J.; Álvarez, H. J.; Palomares, N.; Mata, E.; Moraleda, J.; Menchén, G.; Fernández Martín, S.; Salazar-García, D. C.; Odriozola, C.; Benito, M. y LÓPEZ SÁEZ, J. A. (2014): "Aportaciones hidrogeológicas al estudio arqueológico de los orígenes del Bronce de La Mancha: la cueva monumentalizada de Castillejo del Bonete (Terrinches, Ciudad Real-España)", Trabajos de Prehistoria, 71 (1), pp. 76-94.

Benítez de Lugo, L.; SÁnchez SÁnchez, J.; FernÁndez Montoro, J. L.; Rodríguez Morales, J.; Álvarez, H. J.; Mata, E. y Moraleda, J. (2012): "Excavaciones en la Vía de los Vasos de Vicarello. A Gades Romam, entre las estaciones de Mariana y Mentesa (Puebla del Príncipe, Villanueva de la Fuente, Ciudad Real", Archivo Español de Arqueología, 85, pp. 81-97.

BrandHERM, D. (2003): Die Dolche und Stabdolche der Steinkupfer-und der älteren bronzezeit auf der Iberischen Halbinsel. Prähistorische Bronzefunde. Abteilung VI. Stuttgart: Franz Steiner.

BRONK, C. (2009): "Bayesian analysis of radiocarbon dates", Radiocarbon, 51 (1), pp. 337-360.

Chernyshev, I. V.; Chugaev, A. V. y Shatagin, K. N. (2007): "High-Precision Pb Isotope Analysis by Multicollector-ICP-Mass-Spectrometry using 205Tl/ $203 \mathrm{Tl}$ normalization: Optimization and Calibration of the Method for the Studies of Pb Isotope Variations", Geochemistry International, 45 (11), pp. 1065-1076.

http://dx.doi.org/10.1134/S0016702907110018

DeliBes, G. (1977): El vaso campaniforme en la Meseta Norte española. Serie Studia Archaeologica, 46. Valladolid: Univ. de Valladolid.
Fernández-Miranda, M.; Fernández-Posse, M.a D.; Martín, C.; Montero, I. y Rovira, S. (1996): "Changes in Bronze Age metallurgy as depicted by laboratory analysis: The 'La Mancha' (Spain) model”. En Demirci, S.; ÖZer, A. M. y SuMMERS, G. D. (eds.): ARCHAEOMETRY 94. 29th International Symposium on Archaeometry. Ankara, pp. 23-34.

Fernández-Posse, M.a D.; Martín, C. y Montero, I. (1999): "Meseta Sur". En Delibes, G. y MoNTERO, I. (eds.): Las primeras etapas metalúrgicas de la Peninsula Ibérica. II. Estudios Regionales. Madrid: Fundación Ortega y Gasset-Ministerio de Cultura, pp. 217-239.

Hunt, M.; Contreras, F. y Arboledas, L. (2011): "La Procedencia de los Recursos Minerales en el Poblado de la Edad de Bronce de Peñalosa (Baños de la Encina, Jaén): Resultados de Análisis de Isótopos de Plomo". En Actas V Congreso Internacional sobre Mineria y Metalurgia Históricas en el Suroeste Europeo (León, 2008). Libro en Homenaje a C. Domergue. Madrid: SEDPGYM, pp. 290-310.

Montero, I. (1999): "Sureste". En Delibes, G. y MONTERO, I. (eds.): Las primeras etapas metalúrgicas de la Peninsula Ibérica. II. Estudios Regionales. Madrid: Fundación Ortega y Gasset-Ministerio de Cultura, pp. 333-357.

Montero, I. y Murillo-Barroso, M. (2010): "La producción metalúrgica en las sociedades argáricas y sus implicaciones sociales: una propuesta de investigación”, Menga. Revista de Prehistoria de Andalucia, 1, pp. 37-51.

NÁjera, T.; Molina, F.; Sánchez Romero, M. y ARANDA, G. (2006): "Un enterramiento infantil singular en el yacimiento de la Edad del Bronce de la Motilla del Azuer (Daimiel, Ciudad Real)", Trabajos de Prehistoria, 63 (1), pp. 149-156.

Reimer, P. J.; BARD, E.; BAYliss; A.; Beck, J. W.; Blackwell, P. G.; Bronk Ramsey, C.; GrooTes, P. M.; Guilderson, T. P.; Haflidason, L.; Hajdas, I.; Hattz, C.; Heaton, T. J.; Hoffman, D. L.; Hogg, A. G.; Hughen, K. A.; Kaiser, K. F.; Kromer, B.; Manning, S. W.; NiU, M.; ReIMER, R. W.; Richards, D. A.; Scott, E. M.; Southon, J. R.; StafF, R. A.; TuRney, C. S. M. y VAN DER Plicht, J. (2013): "IntCal13 and Marine13 Radiocarbon Age Calibration Curves 050,000 Years cal BP", Radiocarbon, 55 (4), pp. 1869-1887. http://dx.doi.org/10.2458/azu_js_rc.55.16947

Rovira, S. y Gómez Ramos, P. (2003): Las Primeras Etapas Metalúrgicas en la Peninsula Ibérica. III. Estudios metalográficos. Madrid. 
Rovira, S.; Montero, I. y Consuegra, S. (1997): Las primeras etapas metalúrgicas en la Peninsula Ibérica. I. Análisis de materiales. Madrid: Instituto Universitario Ortega y Gasset.

Salazar-García, D. C.; Benítez de Lugo, L.; ÁlvaREZ, H. J. y BENITO, M. (2013): "Estudio diacrónico de la dieta de los pobladores antiguos de Terrinches (Ciudad Real) a partir del análisis de isótopos estables sobre restos óseos humanos", Revista Española de Antropología Física, 34, pp. 6-14.

SÁnchez SÁnchez, J.; Benítez de Lugo, L.; Rodríguez Morales, J. y Fernández Montoro, J. L.
(2012): "Nomenclatura viaria antigua. La vía de los Vasos de Vicarello: una Vía Augusta de Hispania", El Nuevo Miliario, 15, pp. 3-21.

Stos-Gale, Z. A.; Hunt, M. y Gale, N. H. (1999): "Análisis elemental de isótopos de plomo de objetos metálicos de Gatas". En CASTRO Martínez, P.; Chapman, R.; Gili i Suriñach, S.; Lull, V.; Micó, R.; Rihuete, C.; Risch, R. y Sanahuja, M. E. (eds.): Proyecto Gatas 2. La Dinámica Arqueológica de la Ocupación Prehistórica. Sevilla: C. de Cultura de la Junta de Andalucía, pp. 347-358. 